\title{
Endogenous Cholinergic Signaling Modulates Sound-Evoked Responses of the Medial Nucleus of the Trapezoid Body
}

\author{
Chao Zhang, ${ }^{1}{ }^{\oplus}$ Nichole L. Beebe, ${ }^{2}{ }^{\oplus}$ Brett R. Schofield, ${ }^{2}$ Michael Pecka, ${ }^{3}$ and ${ }^{\oplus}$ R. Michael Burger ${ }^{1}$ \\ ${ }^{1}$ Department of Biological Sciences, Lehigh University, Bethlehem, Pennsylvania 18015, ${ }^{2}$ Department of Anatomy and Neurobiology, Northeast \\ Ohio Medical University, Rootstown, Ohio 44272, and ${ }^{3}$ Division of Neurobiology, Department Biology II, Ludwig-Maximilians University Munich, \\ Martinsried, D-82152, Germany
}

The medial nucleus of trapezoid body (MNTB) is a major source of inhibition in auditory brainstem circuitry. The MNTB projects well-timed inhibitory output to principal sound-localization nuclei in the superior olive (SOC) as well as other computationally important centers. Acoustic information is conveyed to MNTB neurons through a single calyx of Held excitatory synapse arising from the cochlear nucleus. The encoding efficacy of this large synapse depends on its activity rate, which is primarily determined by sound intensity and stimulus frequency. However, MNTB activity rate is additionally influenced by inhibition and possibly neuromodulatory inputs, albeit their functional role is unclear. Happe and Morley (2004) discovered prominent expression of $\alpha 7 \mathrm{nAChRs}$ in rat SOC, suggesting possible engagement of ACh-mediated modulation of neural activity in the MNTB. However, the existence and nature of this putative modulation have never been physiologically demonstrated. We probed nicotinic cholinergic influences on acoustic responses of MNTB neurons from adult gerbils (Meriones unguiculatus) of either sex. We recorded tone-evoked MNTB single-neuron activity in vivo using extracellular single-unit recording. Piggyback multibarrel electrodes enabled pharmacological manipulation of nAChRs by reversibly applying antagonists to two receptor types, $\alpha 7$ and $\alpha 4 \beta 2$. We observed that tone-evoked responses are dependent on ACh modulation by both nAChR subtypes. Spontaneous activity was not affected by antagonist application. Functionally, we demonstrate that ACh contributes to sustaining high discharge rates and enhances signal encoding efficacy. Additionally, we report anatomic evidence revealing novel cholinergic projections to MNTB arising from pontine and superior olivary nuclei.

Key words: cholinergic projection; medial nucleus of trapezoid body; nAChRs; synaptic modulation

Significance Statement

This study is the first to physiologically probe how acetylcholine, a pervasive neuromodulator in the brain, influences the encoding of acoustic information by the medial nucleus of trapezoid body, the most prominent source of inhibition in brainstem sound-localization circuitry. We demonstrate that this cholinergic input enhances neural discrimination of tones from noise stimuli, which may contribute to processing important acoustic signals, such as speech. Additionally, we describe novel anatomic projections providing cholinergic input to the MNTB. Together, these findings shed new light on the contribution of neuromodulation to fundamental computational processes in auditory brainstem circuitry and to a more holistic understanding of modulatory influences in sensory processing.

Received June 28, 2020; revised 0ct. 29, 2020; accepted Nov. 21, 2020.

Author contributions: C.Z., N.L.B., M.P., B.R.S., and R.M.B. designed research; C.Z., N.L.B., and R.M.B. performed research; C.Z., N.L.B., and B.R.S. analyzed data; C.Z. wrote the first draft of the paper; C.Z., N.L.B., M.P., B.R.S., and R.M.B. edited the paper; C.Z. and R.M.B. wrote the paper; M.P. contributed unpublished reagents/analytic tools.

This work was supported by National Institutes of Health/National Institute on Deafness and Other Communication Disorders Grant R15 DC016461 to R.M.B., National Institutes of Health Grant R01 DC004391 to B.R.S., Alexander V. Humboldt foundation to M.P. and R.M.B., and College of Arts \& Sciences Graduate Student Research Grant and Gordon C. Thorne fellowship from Lehigh University to C.Z. We thank Dr. Julie Haas for the training of analytical tools; Dr. Cornelia Kopp-Scheinpflug for guidance in recording technique; Sonia Weimann and Lashaka Jones for insights and advice; and Inka Leprince, Paul Asadourian, Elise Esposito, and Cassidy Zane for contributions to the project.

The authors declare no competing financial interests.

Correspondence should be addressed to R. Michael Burger at rmb206@lehigh.edu.

https://doi.org/10.1523/JNEUROSCI.1633-20.2020

Copyright $\odot 2021$ the authors

\section{Introduction}

The superior olivary complex (SOC) is a major hub of ascending and descending auditory circuitry; and in mammals, it is most studied for its function in processing sound location information. Among its nuclei, the medial nucleus of trapezoid body (MNTB) provides the principal source of inhibitory glycinergic afferents to other SOC structures. The MNTB receives soundevoked excitation from the contralateral cochlear nucleus (CN), thus converting excitation to inhibition with remarkable fidelity. This glycinergic output is conveyed to neurons in several nuclei, including the medial superior olive (MSO) (Adams and Mugnaini, 1990), lateral superior olive (LSO) (Spangler et al., 1985; Banks and Smith, 1992), and superior paraolivary 
nucleus (SPN) (Sommer et al., 1993). This inhibition is important for computing temporal and intensity cues for the auditory system (Park et al., 1996; Brand et al., 2002; Pecka et al., 2008; Kopp-Scheinpflug et al., 2011; Altieri et al., 2014; Koka and Tollin, 2014; Kramer et al., 2014).

Enabling high reliability and temporal precision of MNTB neurons is its excitatory input via a single large calyx of Held synapse that secures afferent signal transmission between $\mathrm{CN}$ and MNTB. Because the rested calyx typically generates synaptic current many times larger than required for threshold (Borst et al., 1995), it was thought to confer $100 \%$ reliability on this synapse (McLaughlin et al., 2008). However, in mouse and gerbil studies, failures at this synapse were observed when driven at very high rates (Kopp-Scheinpflug et al., 2003a, b; Hermann et al., 2007; Lorteije et al., 2009; Wang et al., 2010). In addition, MNTB reliability may be further challenged in cluttered acoustic environments, where auditory circuitry must differentiate signal from noise (Holdstock, 1982; Willmore et al., 2014), although few studies have tested MNTB responses using noise. Computational stability in acoustically complex scenarios requires auditory neurons to adapt to rapid variations in sound level or signal-to-noise $(\mathrm{S} / \mathrm{N})$ ratio (Sollini and Chadderton, 2016; Teschner et al., 2016). One possible adaptive mechanism is the contribution of modulatory circuitry that could enhance computational performance. Modulatory circuits have been demonstrated to provide rapid feedback to sensory neurons in accordance with stimulus dynamics (Scheler, 2004; Marder, 2012; Stange et al., 2013; Gómez-Nieto et al., 2014; Goyer et al., 2016; Jacob and Nienborg, 2018; Gleiss et al., 2019). However, little attention has been directed at probing the potential involvement of broadly projecting modulatory neurotransmitter systems in the MNTB.

A candidate modulatory system that may be brought to bear on computations in MNTB derives from cholinergic circuitry. Happe and Morley (2004) showed that nAChRs are prominently expressed in rat SOC, which suggests a role for ACh to influence acoustic responses. nAChRs have been demonstrated to influence neuron excitability postsynaptically (Oertel and Fujino, 2001) and affect neurotransmitter release (McGehee et al., 1995; Metherate, 2011). Cholinergic inputs have been shown to modulate processing in many nuclei of the central auditory system, including the auditory cortex (Metherate et al., 1990; Metherate and Ashe, 1993; Froemke et al., 2007), medial geniculate body (Woolf and Butcher, 1986; Sottile et al., 2017), inferior colliculus (IC) (Farley et al., 1983; Oliver and Beckius, 1993), and CN (Oertel and Fujino, 2001; Gillet et al., 2018; Kuenzel, 2019). Remarkably, despite welldocumented cholinergic influences throughout the auditory pathway, to our knowledge, no physiological investigation has been conducted on cholinergic modulation in the MNTB.

In the current study, we anatomically identified sources of cholinergic projections to the MNTB. In addition, we recorded MNTB neuron responses to acoustic stimuli in the adult gerbil in vivo while performing pharmacological manipulations of nAChRs. We show that endogenous nAChR activity differentially modulates responses to tone and noise stimuli. Our data strongly suggest that cholinergic signaling may function to influence the ability of MNTB neurons to sustain robust encoding of tone stimuli in the presence of a noisy background.

\section{Materials and Methods}

Surgical procedure. All procedures conducted were in compliance with Public Health Service and Institutional Animal Care and Use
Committee guidelines. Adult Mongolian gerbils (Meriones unguiculatus) aged at least 3 months of either sex were used in all experiments. Initial anesthesia was administered with an intraperitoneal injection $(5 \mathrm{ml} / \mathrm{kg}$ body weight) of a mixture consisting $20 \%$ ketamine $(100 \mathrm{mg} / \mathrm{ml})$ and $2 \%$ xylazine $(100 \mathrm{mg} / \mathrm{ml})$ in $0.9 \% \mathrm{NaCl}$ solution (yielding a final dose of $100 \mathrm{mg} / \mathrm{kg}$ body weight for ketamine and $10 \mathrm{mg} / \mathrm{kg}$ body weight for xylazine). The anesthetic depth was constantly monitored by assessing muscle tone and respiration rate. To maintain narcosis, supplemental doses $(0.05-0.10 \mathrm{ml})$ were injected subcutaneously every $30 \mathrm{~min}$ or whenever necessary. Subjects were transferred to a sound-attenuation booth (Industrial Acoustics) and mounted in a custom-made stereotaxic instrument. Body temperature was maintained at $37^{\circ} \mathrm{C}-39^{\circ} \mathrm{C}$ by a heating pad through a homeothermic controller. For terminal physiological experiments, a large craniotomy was performed on interparietal bone and caudal to the transverse sinus. The dura was partially opened to expose the brain tissue. The underlying cerebellum was partially removed through aspiration to expose the floor of the fourth ventricle; $0.9 \%$ saline was regularly applied to the opening to prevent dehydration of the brain surface. When the recording was finished, animals were injected with $0.2 \mathrm{ml} / \mathrm{kg}$ body weight Somnasol euthanasia solution (Henry Schein Medical) intraperitoneally (yielding a final dose of $78 \mathrm{mg} / \mathrm{kg}$ body weight for pentobarbital sodium and $10 \mathrm{mg} / \mathrm{kg}$ body weight for phenytoin sodium) and perfused with PBS intracardially followed by $4 \%$ PFA in PBS. The brains were then postfixed in the latter solution at $4^{\circ} \mathrm{C}$ overnight for histologic processing. For survival experiments requiring survival of at least $48 \mathrm{~h}$ for anatomic study, the craniotomy was restricted to no more than $\sim 5 \mathrm{~mm}$ in diameter over the lateral portion of the interparietal bone. In these cases, the cerebellum was kept intact. After the retrograde tracers were deposited, the craniotomy was covered with aseptic silicone gel and the skin was sutured with Vetbond glue $(3 \mathrm{M})$. The animals then recovered on a heating pad under frequent monitoring for $24 \mathrm{~h}$. Additional analgesic measures were applied during this period if necessary. After $48-72 \mathrm{~h}$, the animals were anesthetized and perfused as described above. The brains were harvested and maintained in $30 \%$ sucrose PBS until processing for immunostaining.

Immunohistochemistry. After removal of cerebral cortex and cerebellum, the brain was sectioned on a Vibratome or frozen and cut on a sliding microtome into $40-50 \mu \mathrm{m}$ sections in the transverse or sagittal plane. Sections were treated in $0.4 \%$ Triton X-100 in PBS $(0.9 \% \mathrm{NaCl}$ in $0.01 \mathrm{M}$ $\mathrm{PB}$ ) for $30 \mathrm{~min}$ (all steps at room temperature unless noted). After three 5 min washes in PBS, the tissue was treated with $20 \%$ normal rabbit serum with $0.1 \%$ Triton X-100 in PBS for $1 \mathrm{~h}$. Goat anti-ChAT polyclonal antibody (Chemicon $\mathrm{AB} 144 \mathrm{P}$ ) was applied with $0.1 \%$ Triton X-100 and $1 \%$ normal rabbit serum in PBS for $24-72 \mathrm{~h}$ at $4^{\circ} \mathrm{C}$. The concentration of primary antibody varied from 1:100 to 1:400. Following three $5 \mathrm{~min}$ washes in PBS, the tissue was incubated for $1 \mathrm{~h}$ with a secondary antibody (biotinylated rabbit anti-goat IgG, BA-5000, Vector Lab), at a 1:100 concentration with $1 \%$ normal rabbit serum in PBS. Following three additional 5 min washes, tissue was incubated with an AlexaFluor-647labeled streptavidin (1:100; Invitrogen, S-21374) for $1 \mathrm{~h}$ at room temperature. The sections were rinsed in PBS, then mounted on gelatin-coated slides and allowed to dry, and then coverslipped with DPX (Sigma Millipore).

Acoustic stimulation and retrograde tracer deposition in situ at MNTB. Acoustic stimuli were digitally generated using TDT system III commanded through SPIKE, a custom-made software used to simultaneously collect spike time and analog chart recording data. The stimuli were attenuated to desired levels before delivery to earphones. A low impedance glass search electrode $(<1 \mathrm{~m} \Omega)$ filled with $1 \mathrm{~m} \mathrm{NaCl}$ was first advanced using a remotely driven actuator into the brainstem to map the approximate borders of MNTB. While the animal was given $100 \mathrm{~ms}$ broadband noise burst, MNTB-containing area was identified based on the presence of sustained contralaterally evoked responses. Once the location was confirmed, the search electrode was replaced by a low impedance glass pipette loaded with retrograde tracer at the same coordinates. The tracer-containing electrode was first backfilled with mineral oil and then front filled with $300 \mathrm{nl}$ red or green RetroBeads (Lumafluor) diluted 1:10 in 0.9\% saline. Once the pipette was lowered to 
desired depth, 100-200 $\mathrm{nl}$ of tracer was injected using Nanoliter injector (World Precision Instruments).

Analysis of tract-tracing data. Photomicrographs of RetroBeads and ChAT-labeled cells were taken with a Carl Zeiss AxioImager.Z2 microscope with an attached Apotome 2 to provide optical sectioning at $0.5 \mu \mathrm{m}$ depth intervals. Low-magnification images were taken using a $5 \times$ objective without the Apotome, whereas high-magnification images were taken using a $63 \times$ oil-immersion objective $(\mathrm{NA}=1.4)$ with the Apotome. High-magnification images shown are maximum intensity projections of image stacks. Adobe Photoshop was used to colorize, crop, and adjust levels globally.

Plots of RetroBead- and ChAT-labeled cells were created with a Neurolucida system (MBF Biosciences) attached to a Carl Zeiss AxioImager.Z1 microscope. Results from eight tracer deposits were used for the present analysis. Five cases with the greatest amount of retrograde transport were used for quantitative analysis. Every third section through the rostrocaudal extent of each area of interest was examined for $\mathrm{ChAT}^{+}$cells, RetroBead-labeled cells, and cells labeled with both tracer and immunostain markers. The location of each labeled cell was plotted with a symbol indicating the labels present in the cell. After all sections were plotted, the numbers of labeled cells were exported using Neurolucida Explorer, and were further analyzed in Microsoft Excel. Plots to show the distribution of labeled cells were exported from Neurolucida Explorer, and figures were prepared with Adobe Illustrator CC.

In vivo extracellular recording with pharmacological manipulation. The piggyback multibarrel electrodes were crafted by gluing a high impedance $(6-10 \mathrm{M} \Omega)$ glass electrode to a five-barrel glass pipette with tip size of 15-25 $\mu \mathrm{m}$ (Havey and Caspary, 1980; Klug et al., 1999; Burger and Pollak, 2001; Dondzillo et al., 2013). The single-barreled recording electrode protruded $\sim 20-30 \mu \mathrm{m}$ from the multibarrel tip and was loaded with $1 \mathrm{~m} \mathrm{NaCl}$. The multibarrel pipettes were loaded with solutions of pharmacological agents or FluoroGold. Parameterized multibarrel control experiments can be found in Burger and Pollak (2001). When a single cell was encountered, its identity was verified by its contralaterally driven response features and its prepotential containing waveform using an oscilloscope. We constructed each sound presentation to include a $75 \mathrm{~ms}$ delay before tone stimulation period and a $325 \mathrm{~ms}$ silent period after tone offset, followed by an additional $50 \mathrm{~ms}$ dead time where no data were collected in between presentations so that each recording epoch was long enough to fully encompass the recovery of spontaneous responses from poststimulation suppression. This arrangement enabled us to record both spontaneous and tone-evoked activity from the same sweep. Pure tones ranging from 0 to $90 \mathrm{~dB}$ from E.A.R. 3A headphones were coupled to the external auditory meatus with tubes and calibrated using a 1/4-inch free field microphone and a microphone preamp (model 2221, Larson Davis). Stimuli were delivered across a range of frequencies $(100 \mathrm{~Hz}$ to $\sim 10 \mathrm{kHz}$ ) to determine spontaneous firing rate (FR), threshold and characteristic frequency (CF). The spontaneous FR was calculated by averaging the FR before stimulation onset across all stimulation sweeps. Initially, approximate CF was determined audio-visually. Then we presented tones over a narrow frequency range ( $\pm 10-50$ $\mathrm{Hz}$ re: center of estimated $\mathrm{CF}$ ) at a range of intensities to determine $\mathrm{CF}$ empirically. Thresholds were defined as the lowest intensities eliciting at least a $10 \%$ increase in APs over spontaneous firing during the tone (one-tailed paired Student's $t$ test, $p<0.05$ ). Once these parameters were obtained, the rate-level function (RLF) was generated by recording action potentials during contralateral pure tone stimulation at $\mathrm{CF}$ across a range of intensities sufficient to sample the entire dynamic range in $5-10$ steps. The length of stimulation was $50 \mathrm{~ms}$ so that at least 5 cycles at each cell's CF were included. The broadband noise in $\mathrm{S} / \mathrm{N}$ experiments were $\pm 10 \mathrm{kHz}$ centered at CF presented at $20 \mathrm{~dB}$ re: noise threshold (e.g., typically 20-30 dB above tone threshold; see Fig. 6A). For pharmacological manipulations, the drugs were administered through iontophoresis with current in the 25-100 nA range (Burger and Pollak, 2001; Coleman et al., 2011). The pharmacological agents used were $\alpha 4 \beta 2$ nAChRs-specific antagonist dihydro- $\beta$-erythroidine hydrobromide (DH $\beta$ E, $40 \mathrm{~mm}$, Tocris), and $\alpha 7 \mathrm{nAChRs}$-specific antagonist methyllycaconitine (MLA, $20 \mathrm{~mm}$, Tocris), $150 \mathrm{~mm} \mathrm{NaCl}$ was used as vehicle with
$\mathrm{pH}$ adjusted to 4.5. When the recording was finished, 2\% FluoroGold (diluted with saline) was injected in situ at the recording site for histologic confirmation of the identity of neuron recorded. FluoroGold was injected using an iontophoresis pump (BAB-501, Kation Scientific) with $1.5 \mu$ A current and $7 \mathrm{~s}$ on/off pulse cycle.

Data acquisition. The cellular analog signal was amplified (Neuroprobe amplifier 1600, A-M systems), and bandpass filtered (model 3360, KrohnHite). Spikes were detected in the output waveform with a window discriminator (model 121 window discriminator, World Precision Instruments), and the filtered analog signal was digitized at $\sim 20 \mathrm{kHz}$ by a Tucker Davis RX-6 processor and delivered to the computer. The acoustic waveform and action potentials from single cells were visually monitored using a spiketriggered oscilloscope (Tektronix). The digitized data were fed to SPIKE software and analyzed offline using custom-made programs in MATLAB (The MathWorks).

Experimental design and statistical analyses. Forty MNTB neurons in pharmacological experiments were obtained from 26 adult gerbils, including 11 females and 15 males. We performed a two-tailed paired $t$ test on the percentage change of peak FR before and after drug application between two sexes, and the result showed no significant difference $(p=0.35)$. The vehicle-only treatments were conducted before any pharmacological agent were administered. Because the threshold of neurons varied and the range of sound intensities was fixed, we were able to obtain neuronal activity at higher intensities ( $>40 \mathrm{~dB}$ re: threshold) on 18 MLA-treated (95\%) and $18 \mathrm{DH} \beta$ E-treated neurons (86\%). Among the $21 \mathrm{DH} \beta \mathrm{E}$-treated neurons, four neurons were treated with both MLA and $\mathrm{DH} \beta \mathrm{E}$ in succession to the sole application of $\mathrm{DH} \beta \mathrm{E}$ to investigate the relationship between the two subtypes of nAChRs. The standard separability $(D)$ was calculated as follows:

$$
D=\frac{|F R i+1-F R i|}{\sqrt{\sigma(i+1) \times \sigma(i)}},
$$

where $i$ and $i+1$ are the numbers of adjacent intensity steps, and $\sigma$ is the SD of the FR. The relative standard separability of each neuron was calculated by dividing the standard separability of each intensity by the maximum separability of the neuron. The vector strength (VS), a measure of phase-locking, was calculated as follows:

$$
V S=\frac{1}{n} \sqrt{\left[\sum \sin (\theta i)\right]^{2}+\left[\sum \cos (\theta i)\right]^{2}},
$$

where $\theta$ is the phase angle of spike $i$ in reference to the cycle of stimulus, and $n$ is the total discharge during stimulation window (Goldberg and Brown, 1969). The Rayleigh statistic was calculated as follows:

$$
\text { Rayleigh statistic }=2 n V^{2} .
$$

To eliminate bias in temporal precision measures by onset responses, the first $10 \mathrm{~ms}$ of responses were excluded from the analysis window for calculating VS and Rayleigh statistics. Neurons with Rayleigh values $>13.8$ met the significance criterion for phase-locking at $p<0.001$ (Lu et al., 2001). The dynamic range of the RLF was considered the rising phase of the discharge curve between threshold and peak-activity-eliciting intensity (see Fig. $5 \mathrm{~A}$ ). The intensities at $10 \mathrm{~dB}$ re: threshold and $-10 \mathrm{~dB}$ re: peak-activity-eliciting intensity were chosen as boundaries to assess the slope of dynamic range. The slope was calculated through dividing the difference of FR by the number of $10 \mathrm{~dB}$ steps between these two boundary intensities (Colburn et al., 2003). The sensitivity index, $d$ prime $\left(d^{\prime}\right)$ was used to assess the ability of MNTB neurons to detect pure tone signal embedded in noise (Simpson and Fitter, 1973; Macmillan and Creelman, 2004), which was calculated as follows:

$$
d^{\prime}=\left(F R_{\text {signal }+ \text { noise }}\right)-z\left(F R_{\text {noise only }}\right),
$$

where $z\left(\mathrm{FR}_{\text {signal }}+\right.$ noise $)$ and $z\left(\mathrm{FR}_{\text {noise-only }}\right)$ were the mean $z$ scores of the FR from the middle $50 \mathrm{~ms}$ period with both noise and signal present and 


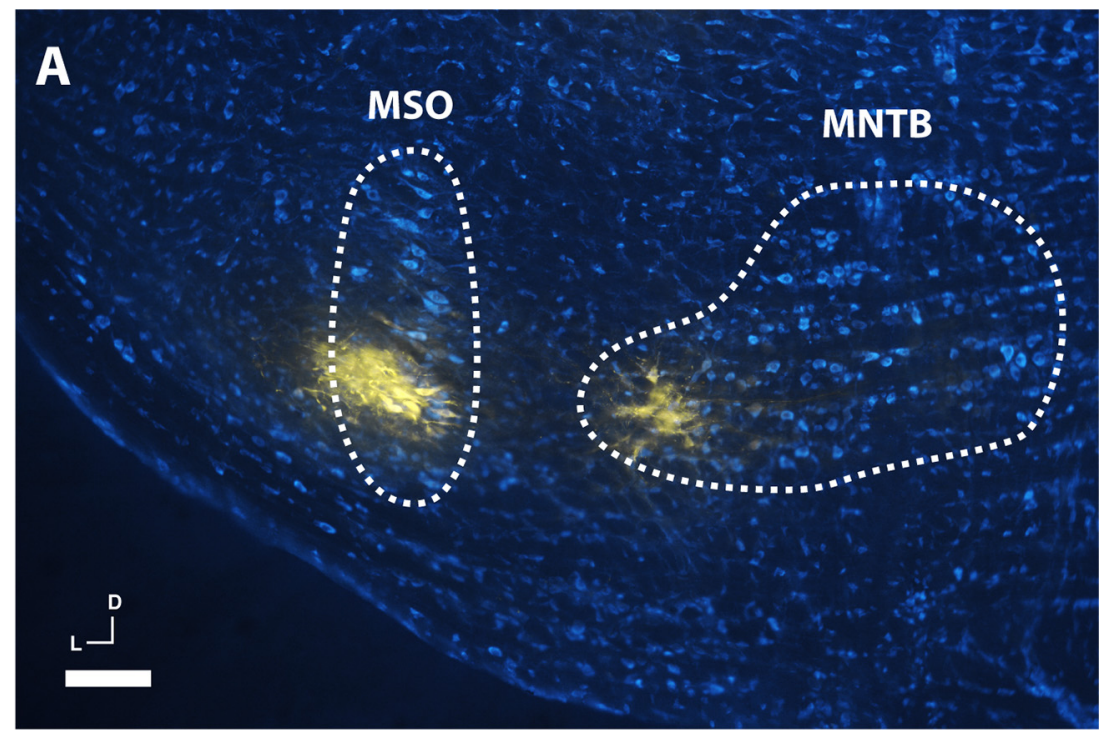

B

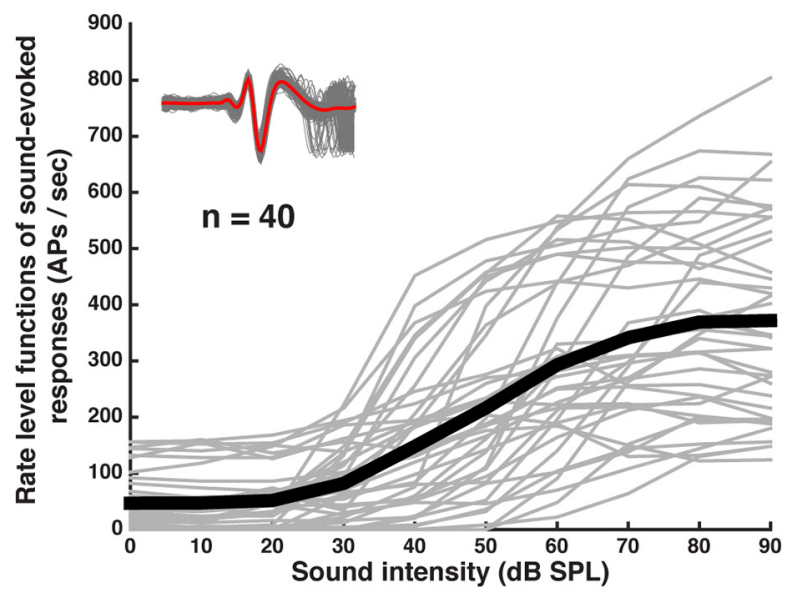

C

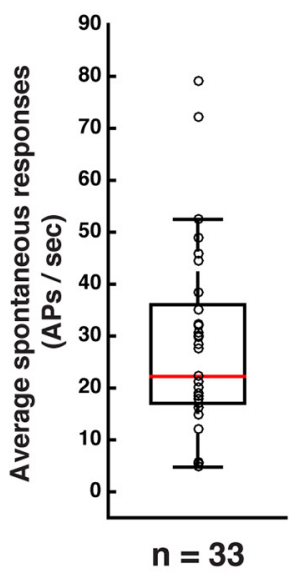

D
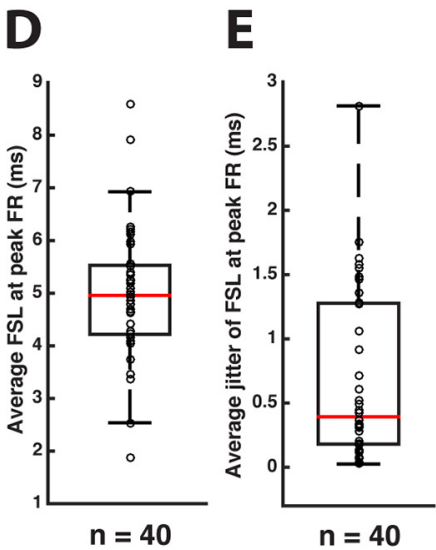

$\mathbf{F}$

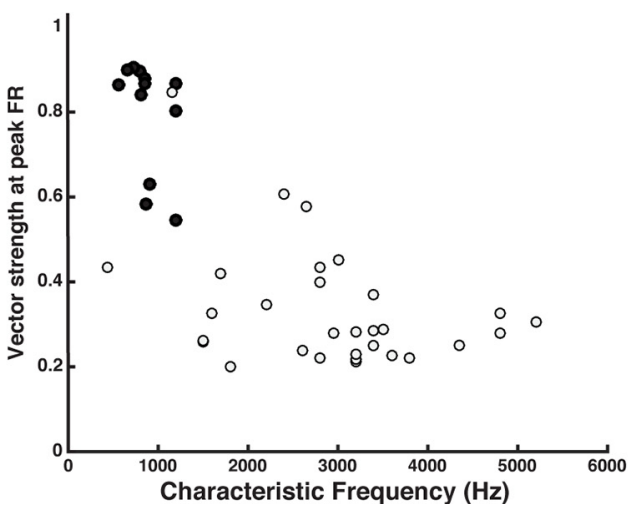

Figure 1. Precise anatomic targeting and physiological validation of MNTB neurons during in vivo extracellular recording. $\boldsymbol{A}$, Histologic confirmation of recording sites. Fluoro-Gold deposited at the end of separate recordings from MNTB and MSO (dotted areas) is clearly separated and localized to target nuclei, confirming precise targeting to recording sites based on acoustically driven responses. $\boldsymbol{B}$, RLFs of 40 neurons recorded reveal tone-evoked responses of MNTB neurons. Bold black line indicates the average RLF. Inset, The averaged waveform of one representative MNTB neuron with a distinct prepotential preceding the action potential thus physiologically confirms the identity of the neuron. $C$, Distribution of spontaneous rates from 33 MNTB neurons with spontaneous firing frequency $>5 \mathrm{~Hz}$ (average $29 \pm 4$ spikes/s). D, Distribution of average FSL from 40 MNTB neurons at intensities that elicited peak FR (average $4.97 \pm 0.21 \mathrm{~ms}$ ). $\boldsymbol{E}$, Distribution of average jitter of FSL from 40 MNTB neurons at intensities that elicited peak FR (average $0.70 \pm 0.11 \mathrm{~ms}$ ). $F$, Distribution of VS from 40 MNTB neurons at intensities that elicited peak FR as a function of CF. Filled circles represent the VS with a Rayleigh value $>13.8$, which is the criteria for phase-locked to tone. with only noise for each intensity from each cell; $d^{\prime}=1$ was considered the threshold of signal detection in noise (Rosen et al., 2010). The population average data in FR, slope steepness, separability, and $d^{\prime}$ are described in the text as mean $\pm \mathrm{SE}$. The normality of the data distribution was assessed using the Shapiro-Wilk test. Comparison of FR, slope steepness among neurons recorded in control, drug, and recovery conditions, and neurons recorded in control, single-drug, and dual-drug conditions was conducted using repeated-measures ANOVA, followed by Tukey's test post hoc for pairwise assessments if distribution was normal, or the Dunn's test if non-normal. Comparisons involving only control and drug conditions were conducted using paired two-tailed student $t$ test if the distribution was normal. Parameters with non-normal distributions were assessed using Wilcoxon paired signed-rank test. The CI was invariably $95 \%$.

\section{Results}

We report on recordings from $40 \mathrm{MNTB}$ neurons, 19 of which were treated with MLA, 21 with $\mathrm{DH} \beta \mathrm{E}$, and 4 with both drugs. RLFs of all neurons were obtained by presenting contralateral pure tones at CF. The recording sites were confirmed histologically post hoc by fluorescent dye deposits at recording sites (Fig. 1A). Physiologic responses to acoustic stimuli were also used to confirm MNTB neuron identity, including, in most cases, the presence of a prepotential waveform, monotonic or mildly nonmonotonic RLFs (Fig. $1 B)$, robust spontaneous firing (29 \pm 4 spikes/s; Fig. 1C), and insensitivity to stimuli at the ipsilateral ear. Tone thresholds were typically between 20 and $50 \mathrm{~dB}$ SPL. Population first spike latency (FSL) was normally distributed (Fig. 1D), and jitter of FSL assumed a non-normal distribution (Fig. 1E). Most neurons with $\mathrm{CF}<1500 \mathrm{~Hz}$ exhibited phase-locked discharges to input frequency (Fig. 1F). These response characteristics are consistent with previous studies of physiological properties of MNTB (Guinan and Li, 1990; Kopp-Scheinpflug et al., 2003a, 2008; Kadner and Berrebi, 2008; Tolnai et al., 2008).

\section{Endogenous cholinergic signaling modulates sound-evoked responses of MNTB}

In order to assess the contribution of endogenous nAChR activity to MNTB responses, we performed in vivo extracellular recording with piggyback multibarrel electrodes that allow for iontophoretic pharmacological manipulation of nAChRs at the recording site. We tested the effects of two nAChR antagonists individually or in combination: MLA, an $\alpha 7 \mathrm{nAChR}$ specific antagonist, and $\mathrm{DH} \beta \mathrm{E}$, an $\alpha 4 \beta 2$ $\mathrm{nAChR}$ specific antagonist. Raster plots in 
Figure $2 A$ show tone-evoked and spontaneous responses of a representative MNTB neuron before, during, and after MLA treatment. When the $\alpha 7 \mathrm{nAChRs}$ were blocked during iontophoresis, tone-evoked response rates decreased, while spontaneous firing (Fig. 2B) was not altered. In this neuron, the control response rate recovered within 10 min of cessation of iontophoresis. This is similarly evident in the RLF, which showed no effect of the antagonist at subthreshold intensities (Fig. 2C). These data suggest that cholinergic signaling contributes to the maintenance of FR in response to tones. To confirm that these prominent effects were because of cholinergic inputs and not an artifact of iontophoresis, we tested the effect of applying iontophoresis current to drug free vehicle for six MNTB neurons, and in no case was FR affected. A representative RLF from a vehicle-only treated neuron is shown in Figure 2D, and the population average maximum FR change during vehicle application was $2.1 \pm 1.4 \%(p=0.32$, paired $t$ test).

In our sample, we were able to sustain recordings long enough to document partial recovery after cessation of iontophoresis on 7 of the MLA-treated neurons (37\%) and 10 of the $\mathrm{DH} \beta \mathrm{E}$-treated neurons (48\%). For population analysis, we selected three suprathreshold intensities in $20 \mathrm{~dB}$ intervals to quantify spike count suppression in the presence of antagonists broadly across the intensity response function. After applying MLA (Fig. 3A), the average FR decreased from $126 \pm 14$ to $96 \pm 15$ spikes/s at $10 \mathrm{~dB}$ re: threshold ( $p=0.00002$, paired $t$ test), from $340 \pm 31$ to $264 \pm 24$ spikes/s ( $p=$ 0.0003 , paired $t$ test) at $30 \mathrm{~dB}$, and from $400 \pm 40 \mathrm{spikes} / \mathrm{s}$ to $327 \pm 29(p=0.0027$, paired $t$ test) at $50 \mathrm{~dB}$. Application of $\mathrm{DH} \beta \mathrm{E}$ (Fig. $3 B$ ) similarly decreased the output rates from $130 \pm 16$ to $98 \pm 16$ spikes/s at $10 \mathrm{~dB}(p=0.03$, paired $t$ test $)$, from $306 \pm 33$ to $240 \pm 27$ spikes/s at $30 \mathrm{~dB}$ ( $p=0.0005$, paired $t$ test), and from $360 \pm 44$ to $306 \pm 35$ spikes/s at $50 \mathrm{~dB}$ re: threshold ( $p=0.0056$, paired $t$ test).

Since similar results were obtained by blocking either $\mathrm{nAChR}$, we tested the relationship between the two receptors by sequentially applying the two antagonists. Because MLA has been shown to also alter $\alpha 4 \beta 2 \mathrm{nAChRs}$ at very high concentration (Mogg et al., 2002), we first applied $\mathrm{DH} \beta \mathrm{E}$ and monitored the sound-evoked responses until reaching a steady state, then added MLA to assess additional effects (Fig. 3C). Four neurons were tested, all of which showed a decreased response after $\mathrm{DH} \beta \mathrm{E}$ application $(p=0.03$, paired $t$ test), followed by further decrease after addition of

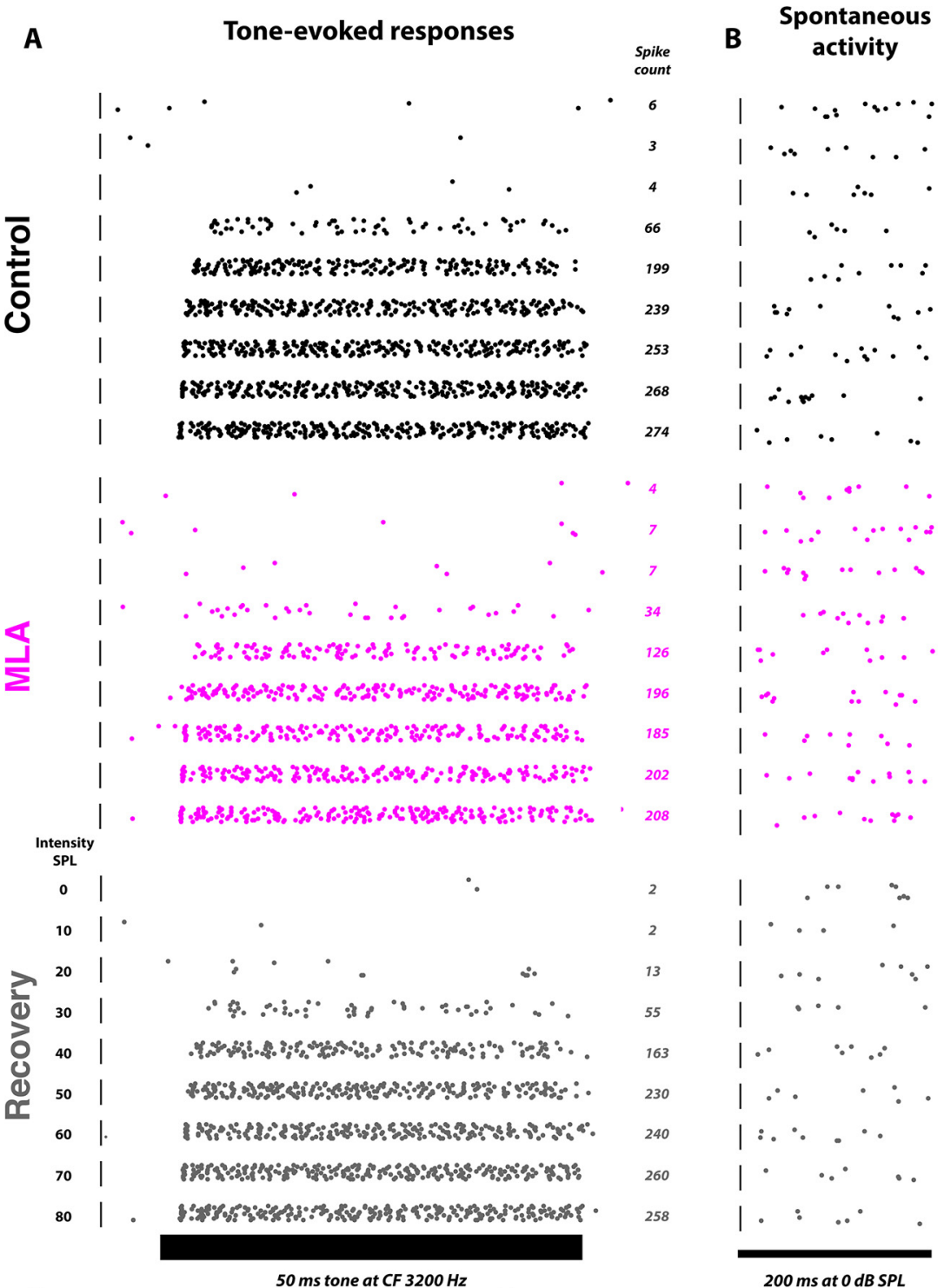

C

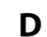

Figure 2. Sound-evoked responses of MNTB neurons decreased after pharmacologically blocking $\alpha 7$ nAChRs. $\boldsymbol{A}$, Raster plots of a representative MNTB neuron over the range of $50 \mathrm{~ms}$ sound stimulation. At CF, responses were significantly reduced at higher intensities after administration of MLA. This decrease was partially reversed within 10 min following cessation of iontophoresis. Scale bar, $50 \mathrm{~ms}$. B. Spontaneous activity averages in each condition exhibit no differences before, during, and after MLA application. Scale bar, $200 \mathrm{~ms}$. C, The RLF of the same neuron with response rate in spikes/s shows MLA-dependent suppression of supra-threshold responses. $\boldsymbol{D}$, RLF of a different neuron during vehicle-only iontophoresis, which evoked no changes in response rate consistent with the population $(n=4)$. 

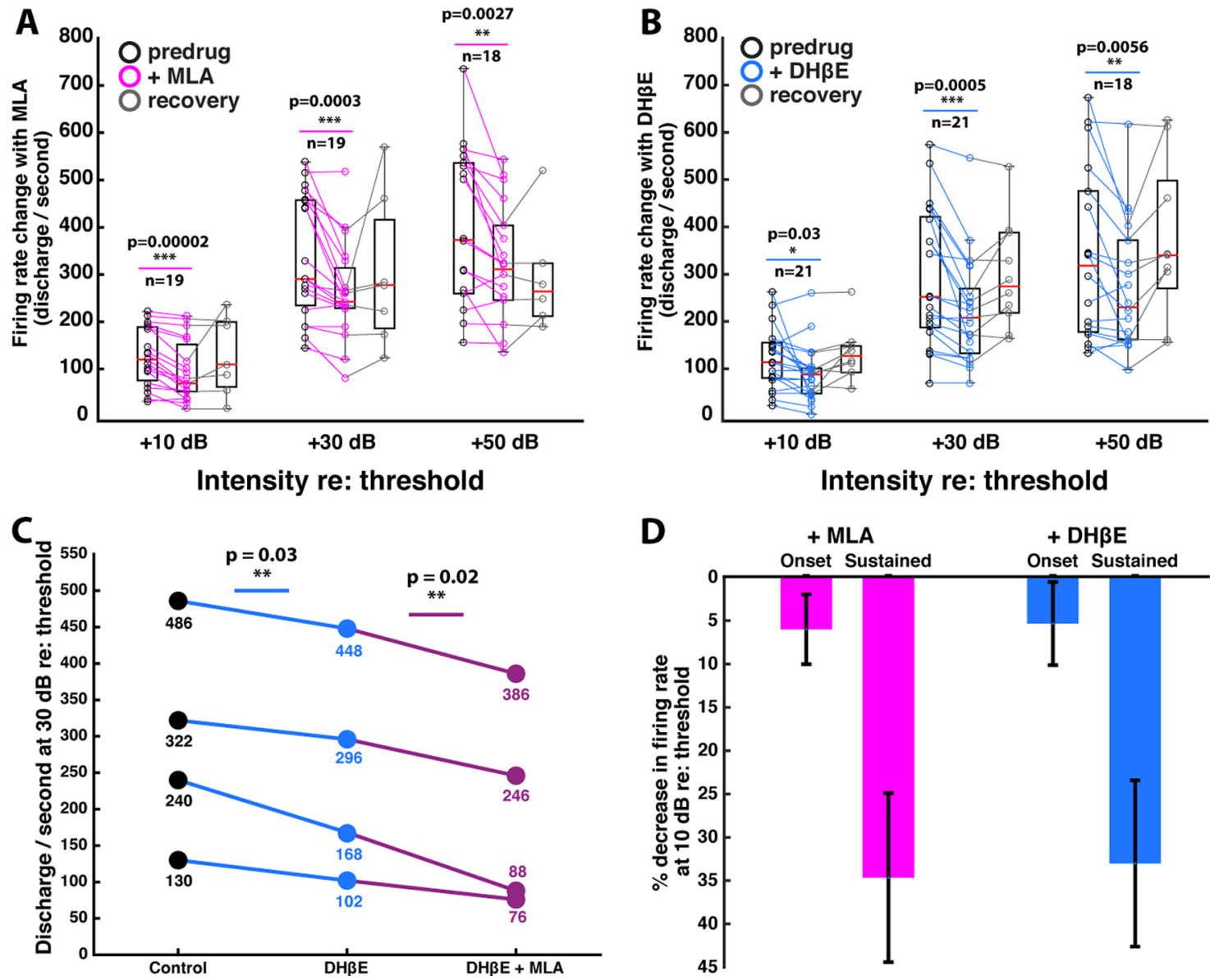

Figure 3. Cholinergic signaling enhances response rates to tones at supra-threshold sound levels. $\boldsymbol{A}$, Population comparison of FR before and after administration of MLA. Three intensities above threshold were chosen. At all three intensities, $\alpha 7 \mathrm{nAChR}$ antagonist decreased the FR significantly. $\boldsymbol{B}$, Population comparison of FR before and after administration of DH $\beta$ E. The intensity selection was the same as treatment in $\boldsymbol{A}$. $\alpha 4 \beta 2 \mathrm{nAChR}$ antagonist treatment showed similar effect to significantly decreased FR. C, Combined $\alpha 7$ and $\alpha 4 \beta 2 \mathrm{nAChRs} \mathrm{block} \mathrm{additively}$ suppressed sound-evoked discharges in four MNTB neurons. Neurons were treated with $\mathrm{DH} \beta \mathrm{E}$ until steady state was obtained (blue circles). Subsequent MLA addition further decreased FR (purple circles). Intensity was $30 \mathrm{~dB}$ re: threshold. repeated-measures ANOVA: $F_{(1.061,3.182)}=20.109, p=0.018$. $\boldsymbol{D}$, Cholinergic signaling differentially affects the onset (10 ms window after first sound-evoked spike) and the sustained firing period after the onset window at $10 \mathrm{~dB}$ re: threshold.

MLA ( $p=0.02$, paired $t$ test). These findings suggest that both nAChR subtypes are expressed in MNTB neurons and are independently affected by the antagonists.

In most cases, qualitative evaluation of nicotinic antagonist influences on tone responses suggested that spiking in the sustained portion of the response was preferentially suppressed compared with onset. Therefore, we analyzed the FR change restricted to the initial $10 \mathrm{~ms}$ of the response (re: onset spike latency) as well as the suppression of sustained responses during the remaining $40 \mathrm{~ms}$ of the stimulus at $10 \mathrm{~dB}$ re: threshold (Fig. $3 D$ ). In the onset window, we observed a $6.0 \pm 4.0 \%$ change $(p=0.15$, $n=19$, paired $t$ test $)$ with MLA and a $5.3 \pm 4.8 \%(p=0.07, n=21$, paired $t$ test) change with $\mathrm{DH} \beta \mathrm{E}$. In contrast, the sustained responses decreased by $34.7 \pm 9.8 \%(p=0.002, n=19$, paired $t$ test $)$ after MLA treatment and $33.0 \pm 9.6 \%(p=0.002, n=21$, paired $t$ test) after $\mathrm{DH} \beta \mathrm{E}$ treatment. This suggests that cholinergic signaling was active over the course of stimulation, but that suppression of the sustained responses contributes the majority of the overall decrease. This finding led us to further investigate the influence of cholinergic components in temporal features of MNTB tone responses.

Cholinergic modulation of temporal dynamics of the response The MNTB calyx is known to reliably preserve temporal features of the acoustic stimulus and input fiber activity. We compared the FSL, jitter of the FSL, and VS before and after antagonist application. FSL measures the duration between the first toneevoked action potential and the onset of the stimulus, while the jitter measures the time fluctuation of FSL. VS measures ongoing synchronization of the tone-evoked response to tone phase. MLA increased FSL of MNTB neurons from $4.88 \pm 0.17 \mathrm{~ms}$ to $5.32 \pm 0.19 \mathrm{~ms}$ (Fig. $4 A ; p=0.023$, paired $t$ test), suggesting that the blockade of $\alpha 7 \mathrm{nAChRs}$ delays the response to stimulus onset. Interestingly, on the population level, the first spike jitter was not affected after applying MLA (Fig. $4 C ; p=0.94$, Wilcoxon paired signed-rank test). Application of $\mathrm{DH} \beta \mathrm{E}$ did not affect the FSL (Fig. $4 B$ ), with $5.05 \pm 0.37 \mathrm{~ms}$ before and $5.38 \pm 0.39 \mathrm{~ms}$ after drug administration ( $p=0.37$, paired $t$ test) nor the average jitter across the population (Fig. $4 D ; p=0.20$, Wilcoxon paired signed-rank test). Furthermore, blocking $\alpha 7 \mathrm{nAChRs}$ did not affect VS for phase-locked neurons at peak discharge $(p=0.69$, Wilcoxon paired signed-rank test), and blocking $\alpha 4 \beta 2 \mathrm{nAChRs}$ did not influence significant VS either $(p=0.63$, Wilcoxon paired signed-rank test). We also assessed VS of all neurons at $10 \mathrm{~dB}$ re: threshold, and application of neither MLA $(p=0.84$, Wilcoxon paired signed-rank test) nor $\mathrm{DH} \beta \mathrm{E}(p=0.20$, Wilcoxon paired signed-rank test) significantly changed VS. Since MNTB is the main source of inhibitory projections to neurons that compute sound localization based on temporal cues, the timing of first spike elicited at MNTB after 

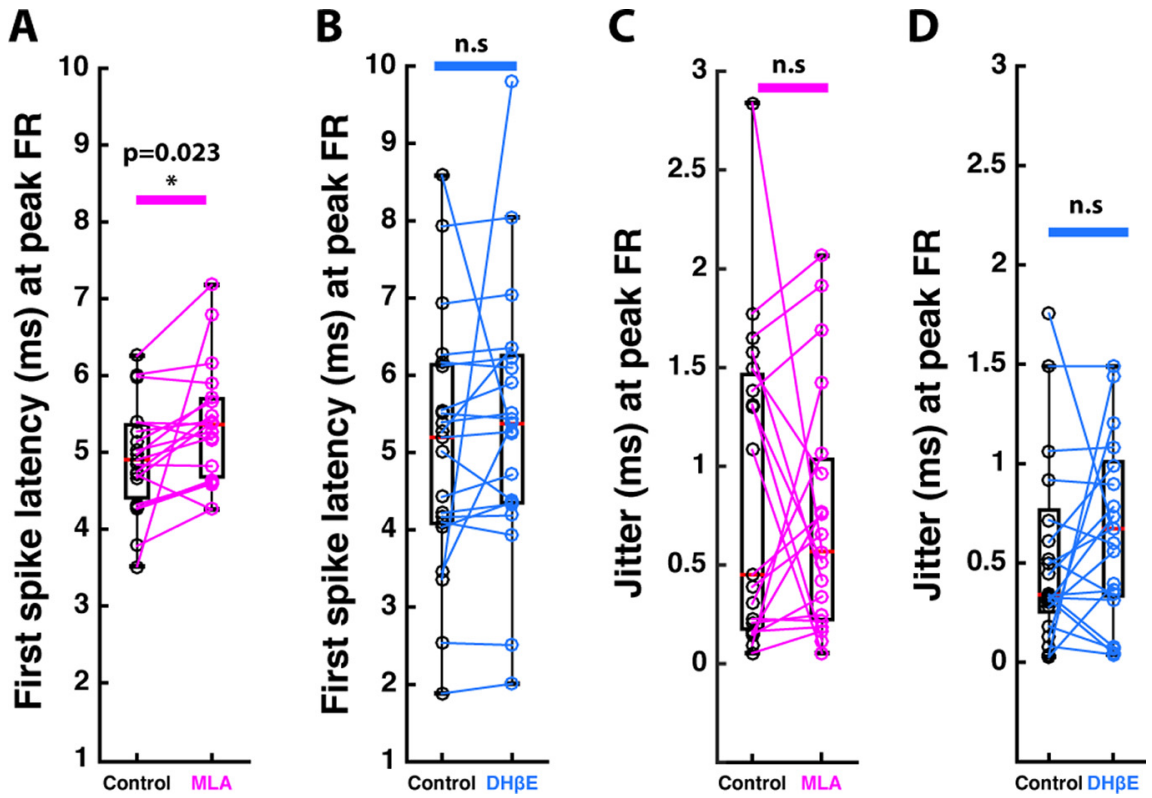

Figure 4. Blocking cholinergic signaling delays FSL without affecting onset jitter of CF tone responses. $A, B$, Population analysis of the FSL at intensities yielding peak responses after blocking nAChRs. FSL increased with $\alpha 7$ antagonist, whereas blocking $\alpha 4 \beta 2$ nAChRs showed no effect. $\mathbf{C}, \mathbf{D}$, The jitter of first spikes elicited was not changed in response to either drug. n.s.: not significant.
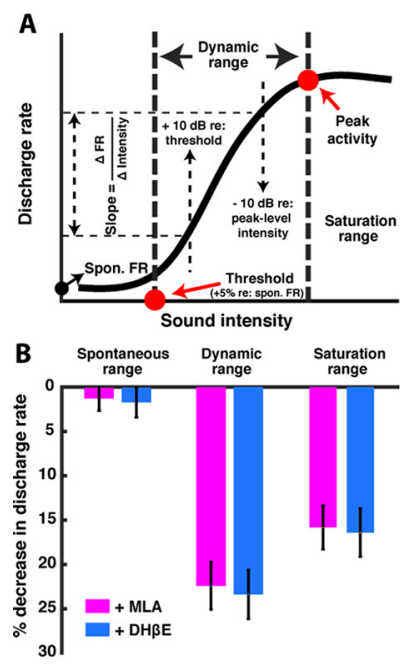
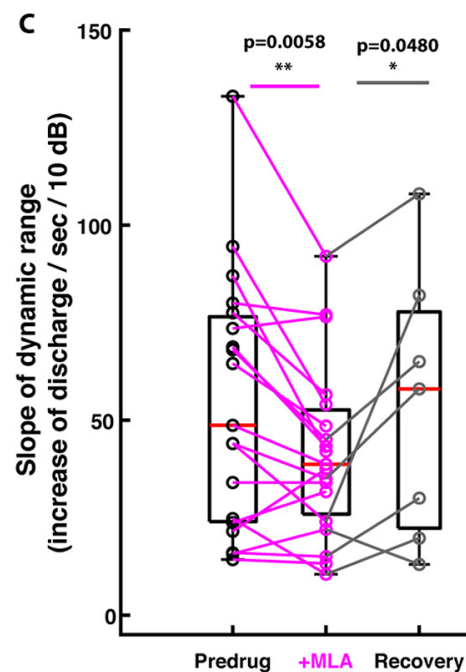
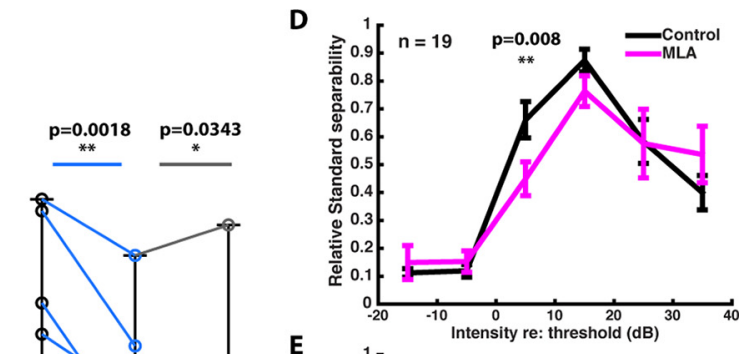

E

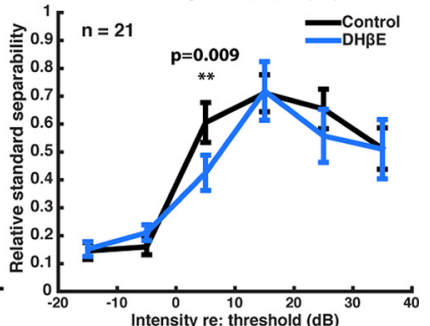

Figure 5. Cholinergic signaling contributes to efficacy of intensity encoding in MNTB. A, Schematic illustration of a typical RLF highlighting three phases of a typical response function. The definition of spontaneous FR, criteria for threshold, and parameters used for slope calculation are explained in detail in Materials and Methods. $\boldsymbol{B}$, Quantitative analysis of relative percentage changes in FR after turning off cholinergic signaling to MNTB using both drugs. Average percent decreases in each of three phases of the response function are presented. Modulation of spontaneous activity was not detected. The strongest discharge suppression occurred during the dynamic portion of the function, and an intermediate decrease was observed during saturation. C, Slopes in the dynamic range were decreased after MLA and DH $\beta$ E application. repeated-measures ANOVA for MLA treatment: $F_{(2,12)}=5.208, p=0.024$; and for DH $\beta$ E treatment: $F_{(1.506,13.551)}=5.352, p=0.026$. D. Relative standard intensity separability by neurons treated with MLA. Separability is measured between adjacent intensities, indicating the ability of level discrimination between the neighboring levels. $\alpha 7 \mathrm{nAChR}$ antagonist decreased neurons' ability to differentiate threshold and $10 \mathrm{~dB}$ re: threshold. $\boldsymbol{E}$, Similar effects were observed after blocking $\alpha 4 \beta 2 \mathrm{nAChRs}$.

stimulation onset is intimately related to the timing of inhibitory output to target SOC neurons.

Endogenous cholinergic signaling affects encoding efficacy at the calyx of Held synapse

The RLFs of MNTB neurons are primarily monotonic and therefore can be viewed as having subthreshold, dynamic, and saturating intensity ranges (Fig. 5A). The results presented thus far suggest that cholinergic signaling to MNTB contributes most to FR at intensities just above threshold. These intensities, ranging from $\sim 10$ to $30 \mathrm{~dB}$ re: threshold, typically fall into the dynamic portion of the function, where the variation in discharge rate is the most sensitive to changes in input level. We compared the percentage reduction in FR in three intensity ranges: subthreshold, dynamic, and saturating (typically $>30 \mathrm{~dB}$ re: threshold; Fig. 5B). Cholinergic components contribute more to the output level in the dynamic range expressed as a percentage of control response rate, with a $22.4 \pm 2.7 \%$ decrease in MLA-treated neurons and $23.4 \pm 2.7 \%$ decrease in $\mathrm{DH} \beta$ E-treated neurons. After the saturating discharge rate was reached, $\alpha 7 \mathrm{nAChRs} \mathrm{contribute}$ to $15.8 \pm 2.5 \%$ and $\alpha 4 \beta 2 \mathrm{nAChRs}$ contribute to $16.4 \pm 2.7 \%$ of discharges. Since the dynamic range is the monotonic phase of the RLF with a positive input-output relationship, the steepness of the linear portion indicates the sensitivity of a neuron to 
A

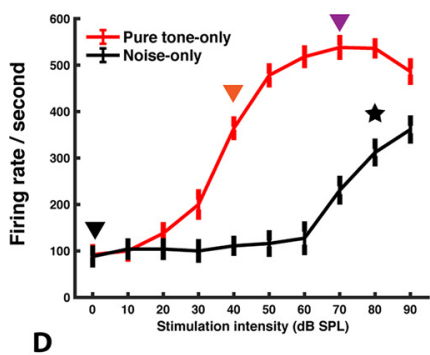

D

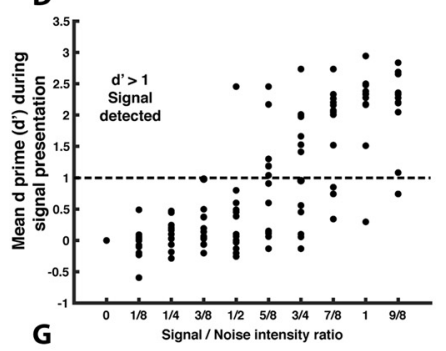

$\mathbf{G}$

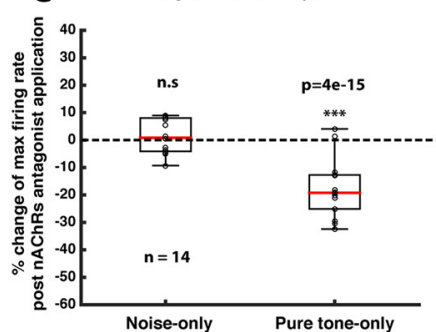

B

Control

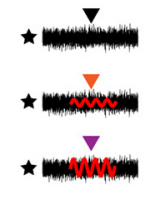

E
C

+ MLA

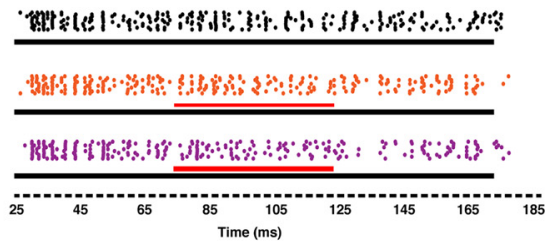

F

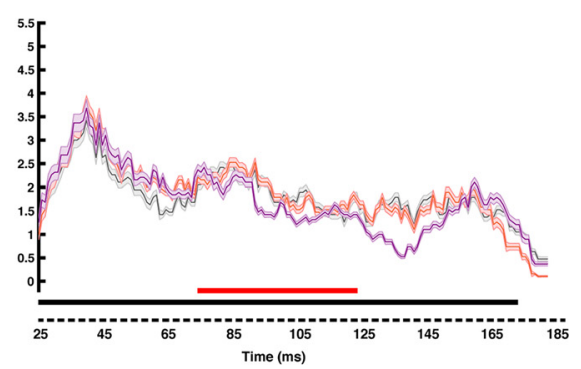

Figure 6. ACh differentially modulates pure tone and noise-only responses. $\boldsymbol{A}$, RLFs in pure tone-only and noise-only condition of the MNTB neuron displayed in $\boldsymbol{B}$ and $\boldsymbol{C}$. Black star represents the noise intensity presented in $\boldsymbol{B}, \boldsymbol{C}, \boldsymbol{E}, \boldsymbol{F}$. Colored triangles represent the selected tone intensities. $\boldsymbol{B}, \boldsymbol{C}$, Raster responses to the tone in noise stimuli with increasing $S / N$. Left, A schematic representation of the stimuli includes embedded $50 \mathrm{~ms}$ (F pure tone signal (red) in 150-ms-wide band frozen noise (black) and their corresponding raster plots before $(\boldsymbol{B})$ and after $(\boldsymbol{C})$ MLA administration. $\boldsymbol{B}, \boldsymbol{C}$, Solid black and red bars along the time axis represent the durations of noise and pure tone stimuli, respectively, where thickness indicates intensity. $\boldsymbol{B}, \boldsymbol{C}$, The rolling mean \pm SE (10 ms window) of discharge counts are shown in $\boldsymbol{E}$ and $\boldsymbol{F}$ with the same time scale. $\boldsymbol{D}$, Population distribution of mean $d^{\prime}$ with respect to $S / N$ intensity ratios. MNTB neurons are more likely to detect signal from noise at higher $\mathrm{S} / \mathrm{N}$ ratios. $\mathbf{G}$, Population analysis of percentage change at peak FR with noise-only and pure tone-only conditions of pooled MLA- and DH $\beta E$ treated MNTB neurons. ACh does not affect the FR when MNTB was only evoked by noise $(p=0.625)$, whereas pure tone evoked FR decreased significantly $(p=0.003)$. n.s.: not significant.

intensity differences and determines its capacity to discriminate neighboring intensities. We therefore assessed the slope of the dynamic range to evaluate intensity encoding competence. We observed a significant decrease of the slope following application of MLA and $\mathrm{DH} \beta \mathrm{E}$ (Fig. $5 \mathrm{C}$ ). The magnitude of decrease was from $43 \pm 5$ to $33 \pm 4 \Delta$ spikes $/ \mathrm{s} / 10 \mathrm{~dB}$ for MLA treatment $(p=0.0019$, Wilcoxon paired signed-rank test), and from $38 \pm 6$ to $29 \pm 5 \Delta$ spikes $/ \mathrm{s} / 10 \mathrm{~dB}$ for $\mathrm{DH} \beta \mathrm{E}$ treatment $(p=0.0031$, Wilcoxon paired signed-rank test).

Intensity discrimination is important for many auditory computations, particularly for detecting signals in noise (Whitmer and Akeroyd, 2011; Teschner et al., 2016). As the RLF slope in the dynamic range was significantly decreased by antagonizing nAChRs, we then asked whether blocking nAChRs affects the neurons' ability to discriminate between neighboring stimulus intensities. We analyzed the influences of ACh on relative standard separability $(D)$, a measure of discrimination that reflects statistical discriminability between intensities based on mean response rates and variances (Beiderbeck et al., 2018). Separability was decreased between threshold and the minimum level above threshold after blocking $\alpha 7 \mathrm{nAChRs}$ (Fig. 5D), and a similar effect of blocking $\alpha 4 \beta 2 \mathrm{nAChRs}$ is shown in Figure 5E. Specifically, the administration of MLA caused a $29.1 \pm 6.5 \%$ decrease in FR at $10 \mathrm{~dB}$ re: threshold, while the magnitude of decrease was $14.4 \pm 4.5 \%$ at $50 \mathrm{~dB}$ re: threshold ( $p=0.027$, paired $t$ test). After applying $\mathrm{DH} \beta \mathrm{E}$, FR decreased by $25.3 \pm 7.3 \%$ at $10 \mathrm{~dB}$ and $15.0 \pm 5 \%$ at $50 \mathrm{~dB}$ re: threshold ( $p=0.046$, paired $t$ test). Both drugs caused the greatest reduction in FR evoked by sounds near or above threshold. This indicates that cholinergic network functions to increase the contrast between subthreshold and suprathreshold intensities by increasing the FR more in the lowintensity portion of the neuron's audible range. Such contrast enhancement is likely to influence the detection of signals in noise. We therefore examined whether ACh activity influenced tone encoding in an acoustic signal-in-noise paradigm.

To test this hypothesis, we first examined the responses of MNTB neurons evoked by pure tones or noise alone. In addition to the difference in FR, thresholds were higher with noise-only stimuli (Fig. 6A). In order to investigate whether ACh contributes to tone detection in noise, we recorded the discharge patterns of MNTB neurons in response to $50 \mathrm{~ms}$ pure tones at $\mathrm{CF}$ embedded in a long duration $(150 \mathrm{~ms})$ broadband frozen noise (Fig. 6B). The intensity of noise stimuli was fixed at $20 \mathrm{~dB}$ re: noise threshold while a broad intensity range of pure tones was presented in $10 \mathrm{~dB}$ randomized steps, yielding dynamically shifting $\mathrm{S} / \mathrm{N}$ ratios. Since noise responses are temporally stochastic, we integrated discharge responses with a $10 \mathrm{~ms}$ shifting time bin moving average throughout the duration of stimulation (Fig. $6 E$ ). Figure $6 A, B, E$ reveals one neuron's firing patterns in response to three $\mathrm{S} / \mathrm{N}$ ratios schematically illustrated in Figure $6 B$. The noise intensity was fixed at $80 \mathrm{~dB}$ SPL (black star) while three different signal intensities were 0,40 , and $70 \mathrm{~dB}$ SPL (black, orange, and purple triangles, respectively). In contrast to noiseonly condition (Fig. 6B,E, black traces), the other two 

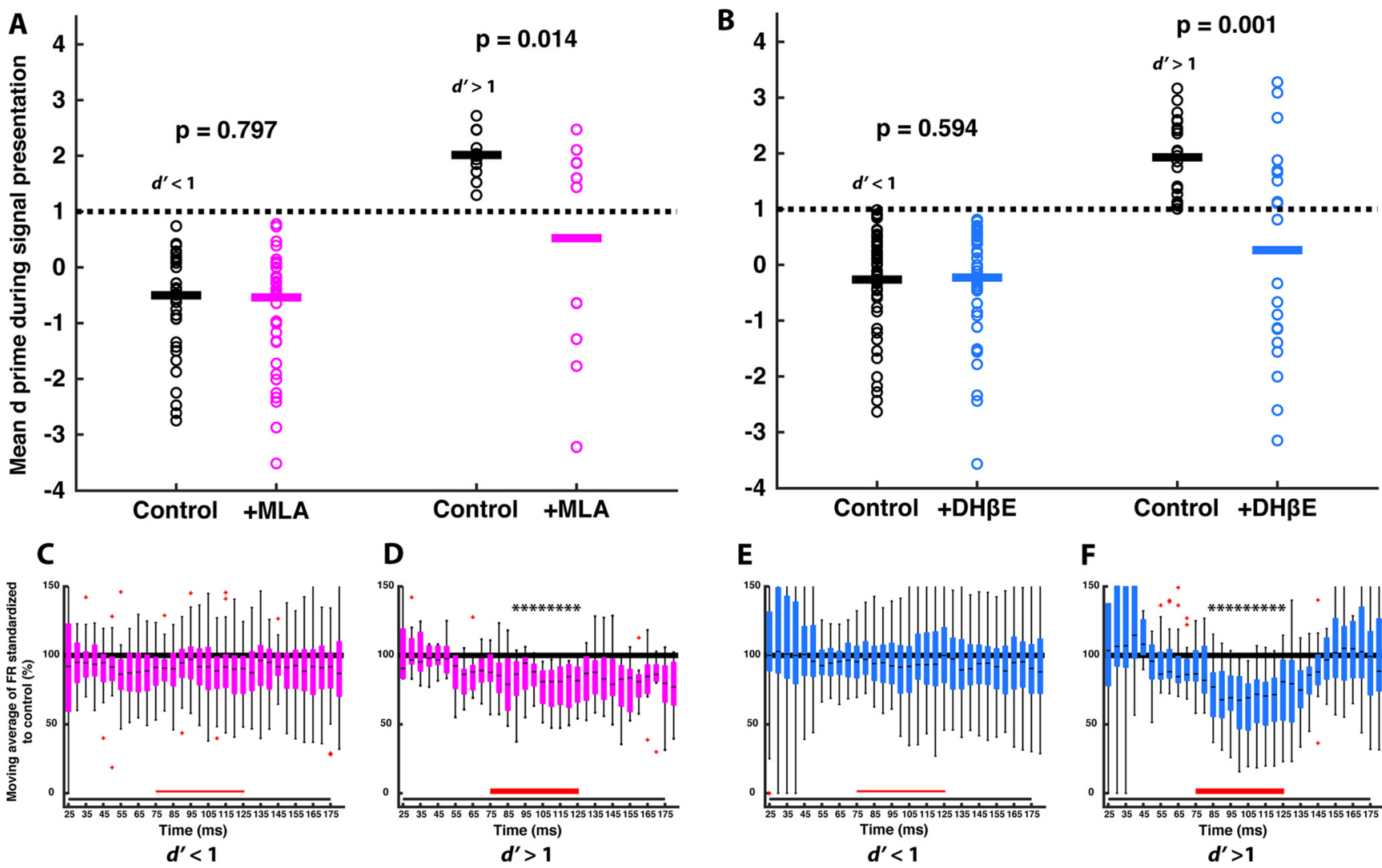

Figure 7. Cholinergic signaling improves tone discrimination in MNTB neurons. $\boldsymbol{A}$, Population analysis of mean $\boldsymbol{d}^{\prime}$ before and after MLA administration. Blocking $\alpha 7$ nAChRs does not change the detection ability below criterion $\mathrm{S} / \mathrm{N}$ ratio stimuli, but significantly degrades the average discrimination ability of detectable stimuli to be below criterion. $\boldsymbol{B}$, DH $\beta$ E evokes a similar loss of discrimination. $\mathbf{C}-\boldsymbol{F}$, Discharge rates of postpharmacological treatment normalized to control condition in 5 ms increments, with each box plot representing the distribution of discharges in each time bin. Length and thickness of black and red bars indicate the relative duration and intensity of sound intensity, respectively. $\boldsymbol{C}, \boldsymbol{E}$, Responses when signals are nondetectable; neither $\alpha 7$ nor $\alpha 4 \beta 2$ nAChRs contribute to signifying tone presence. $\boldsymbol{D}, \boldsymbol{F}$, Both $\alpha 7$ and $\alpha 4 \beta 2$ nAChRs contribute to facilitated tone responses that enable significant differentiation of tones from noise $(p<0.05$, asterisks). $\mathbf{C}-\boldsymbol{F}$, Red crosses are outliners exceeding $1.5 \times$ the interquartile range.

combinations both exhibited transient FR increases during the middle $50 \mathrm{~ms}$ period that included tone stimuli (Fig. $6 B, E$, orange and purple traces). This increase in firing is suggestive of signal detection. During MLA application, this transient preferential tone response was substantially degraded (Fig. 6C), rendering the postdrug discharge patterns of 40 and $70 \mathrm{~dB}$ signal similar to the noise-only response (Fig. $6 F$ ). Therefore, the ability of this neuron to represent the presence of embedded tone in its discharge rate was abolished after pharmacological block of nicotinic signaling.

We then investigated the detection ability of MNTB neurons, as indicated by $d^{\prime}$ values $>1$, to discriminate the middle $50 \mathrm{~ms}$ tone from noise across the population (Fig. 6D). Not surprisingly, we observed prominent tone discrimination with higher S/ $\mathrm{N}$ ratios. We then compared the effect of drug application on $d^{\prime}$ values from responses that were either above or below the discrimination criterion in control as indicated by the dashed line in Figure 6D. With MLA application (Fig. 7A), neural responses to stimuli that failed detection in control showed no change, and remained insensitive to tone presentation (mean $d^{\prime}$; control: -0.50 , MLA: $-0.54, p=0.797$, Student's $t$ test). However, higher $\mathrm{S} / \mathrm{N}$ stimuli that evoked above criterion $d^{\prime}$ values in control showed significantly decreased $d^{\prime}$ values in the presence of MLA (mean $d^{\prime}$; control: 2.02, MLA: 0.52, $p=0.014$, Student's $t$ test). Similarly, application of $\mathrm{DH} \beta \mathrm{E}$ yielded no significant change of $d^{\prime}$ for below criterion responses (mean $d^{\prime}$; control: -0.31 , $\mathrm{DH} \beta \mathrm{E}:-0.27, p=0.594$, Student's $t$ test), while the mean $d^{\prime}$ for detected tones in control decreased from 1.93 to 0.27 in the presence of $\mathrm{DH} \beta \mathrm{E}$ (Fig. $7 B)(p=0.001$, Student's $t$ test). To visualize the population change in discharge patterns more clearly, Figure $7 C F$ shows the drug-treated response rates in box-and-whisker plots normalized to control responses indicated by the black line, where the stimulus-dependent effects during antagonist application can be appreciated. In cases where $d^{\prime}<1$, the discharge patterns during signal presentation showed no difference before and after antagonists administration (Fig. 7C,E). In contrast, we observed that both MLA and $\mathrm{DH} \beta \mathrm{E}$ application yielded significant discharge suppression, but only to stimuli with detectable $\mathrm{S} / \mathrm{N}$ ratios in control. Together, tone detection as indicated by $d^{\prime}$ fell below the discrimination threshold during both drug treatments, suggesting that MNTB neurons' ability to detect signals in noise was significantly degraded when cholinergic inputs were blocked.

MNTB receives cholinergic projections from multiple sounddriven sources

Our physiological data showed strong ACh contributions to suprathreshold but not subthreshold responses, suggesting that cholinergic input may be sound driven. To identify sources of cholinergic input to MNTB, we deposited retrograde tracer (RetroBeads) in the MNTB and examined the regions of brain that contain tracer-filled neurons. Injection sites typically included the MNTB and one or more of the adjacent nuclei of the medial SOC. One injection was completely restricted to the 

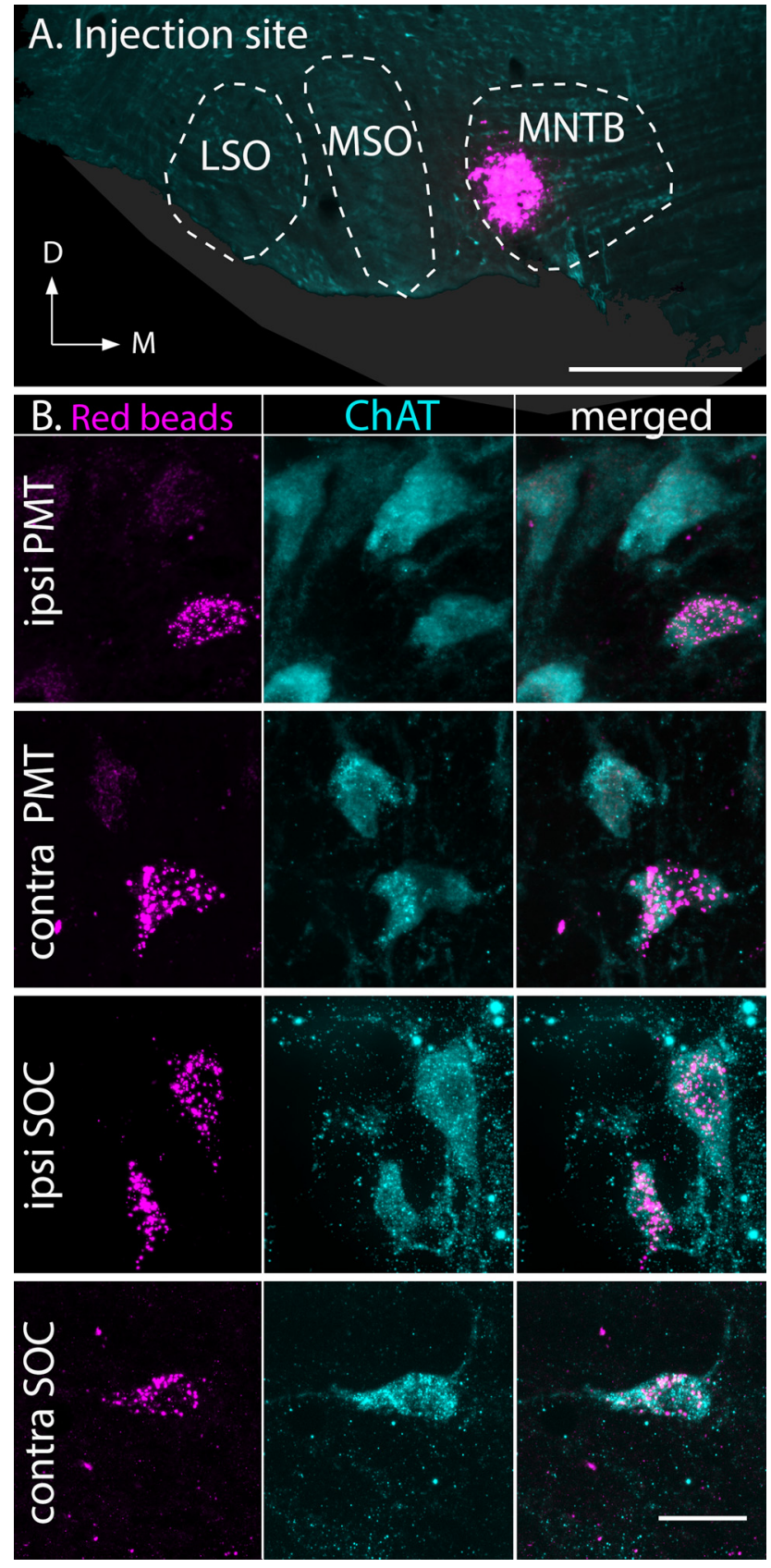

Figure 8. The MNTB receives bilateral cholinergic input from two regions: the $S O C$ and the PPT. A, A deposit of red RetroBeads (magenta) restricted to the lateral part of the left MNTB. The section was stained with anti-ChAT to identify cholinergic cells; a few $\mathrm{ChAT}^{+}$cells are visible between the MNTB and MSO. The ventral surface of the section was damaged during processing, but this section is shown to reveal the maximum dimensions of the tracer deposit. Transverse section: D, dorsal; $M$, medial. Scale bar, $250 \mu \mathrm{m}$. $\boldsymbol{B}$, Retrogradely labeled neurons from the same case illustrated in $\boldsymbol{A}$. Each row represents neurons labeled with red RetroBeads (Red beads, first column) that are also immunostained for ChAT (cyan, second column). "merged" shows the overlap of the channels. Neurons are pictured from the PPT and the SOC, both ipsilateral ("ipsi") and contralateral ("contra") to the injection site. Scale bar, $20 \mu \mathrm{m}$. B, Images were taken with structured illumination.

MNTB (Fig. 8A), allowing us to confirm that the results were not dependent on inclusion of the adjacent nuclei. In all cases, tracer-filled neurons were prominent in the $\mathrm{CN}$ contralateral to the injected MNTB, as well as within the SOC ipsilateral and contralateral to the injection. Interestingly, tracer-labeled neurons were also observed bilaterally in the pontomesencephalic tegmentum (PMT), a midbrain structure that sends cholinergic axons widely across the brain, including to multiple levels of the auditory system (Schofield et al., 2011). By immunostaining the tissue with anti-ChAT antibody to label cholinergic cells, we could identify tracer-labeled cholinergic cells. $\mathrm{ChAT}^{+}$tracer-labeled neurons were present bilaterally in the PMT and the SOC (Fig. $8 B$ ). Each of these areas contained ChAT-negative tracer-labeled cells (not shown). Some of these immunonegative cells were in close proximity to $\mathrm{ChAT}^{+}$cells, suggesting that noncholinergic cells in these nuclei also project to the MNTB.

Very small tracer deposits (e.g., the one confined to the MNTB, shown in Fig. 8) labeled relatively few cells, so we chose 2 cases with larger deposits and more tracer-labeled cells to assess relative sizes of the $\mathrm{ChAT}^{+}$projections. The distributions of labeled cells in these cases were qualitatively similar to that following smaller deposits. Figure 9 shows the distribution of $\mathrm{ChAT}^{+}$ tracer-labeled cells after a tracer deposit that included a large portion of the MNTB and some of the adjacent SPN (Fig. 9, green). The PMT contained the majority $(80 \%$ and $82 \%$ in the 2 cases) of the $\mathrm{ChAT}^{+}$tracer-labeled cells, with the remainder in the SOC. Within the SOC, $\mathrm{ChAT}^{+}$tracer-labeled cells were scattered among the LSO and the periolivary nuclei (Fig. 9, sections 1,12 , and 24). The illustrated case shows a majority of $\mathrm{ChAT}^{+}$ tracer-labeled SOC cells on the side contralateral to the injected SOC; in other cases, the distribution was more evenly spread across the two SOCs. The PMT comprises a laterodorsal tegmental nucleus, contained within the borders of the periaqueductal gray, and a pedunculopontine tegmental nucleus (PPT), outside the periaqueductal gray. $\mathrm{ChAT}^{+}$tracer-labeled cells were present bilaterally in both nuclei, with more cells on the ipsilateral side and, on each side, more cells in the PPT than in the laterodorsal tegmental nucleus.

\section{Discussion}

Our data support four broad conclusions regarding cholinergic modulation of the MNTB. First, we identified two novel cholinergic projections to the MNTB, including a predominant projection arising bilaterally from the PMT and smaller bilateral projections from the SOC (Fig. 10). Second, we demonstrated that ACh contributes to the response magnitude for suprathreshold stimuli but does not influence threshold values or spontaneous spike rates. Third, ACh enhances level discrimination at near threshold intensities. Finally, we demonstrated that cholinergic modulation enhances encoding of tone signals in noise. Here we discuss the implications of these findings in the context of auditory processing more broadly.

\section{Cholinergic modulation is sound-evoked and improves reliability of MNTB neurons}

We demonstrated that activation of $\alpha 7$ or $\alpha 4 \beta 2$ nAChRs contributes to a $15 \%-30 \%$ increase in response rate to tone stimuli. While the sound-evoked responses were substantially modulated, spontaneous firing was not affected by either treatment. These findings led to at least two possible interpretations that are not mutually exclusive. First, the data suggest that the source of cholinergic input to MNTB was itself driven by sound stimulation and therefore only acts at higher intensities. Alternatively, tonic ACh may alter synaptic efficacy or postsynaptic excitability subtly such that its influence is only evident when MNTB neurons are challenged with a stimulus that evokes repetitive firing.

We identified two cholinergic projections to the MNTB, originating from the SOC and PMT. SOC neurons are driven by acoustic stimulation, and at least some provide glycinergic input 

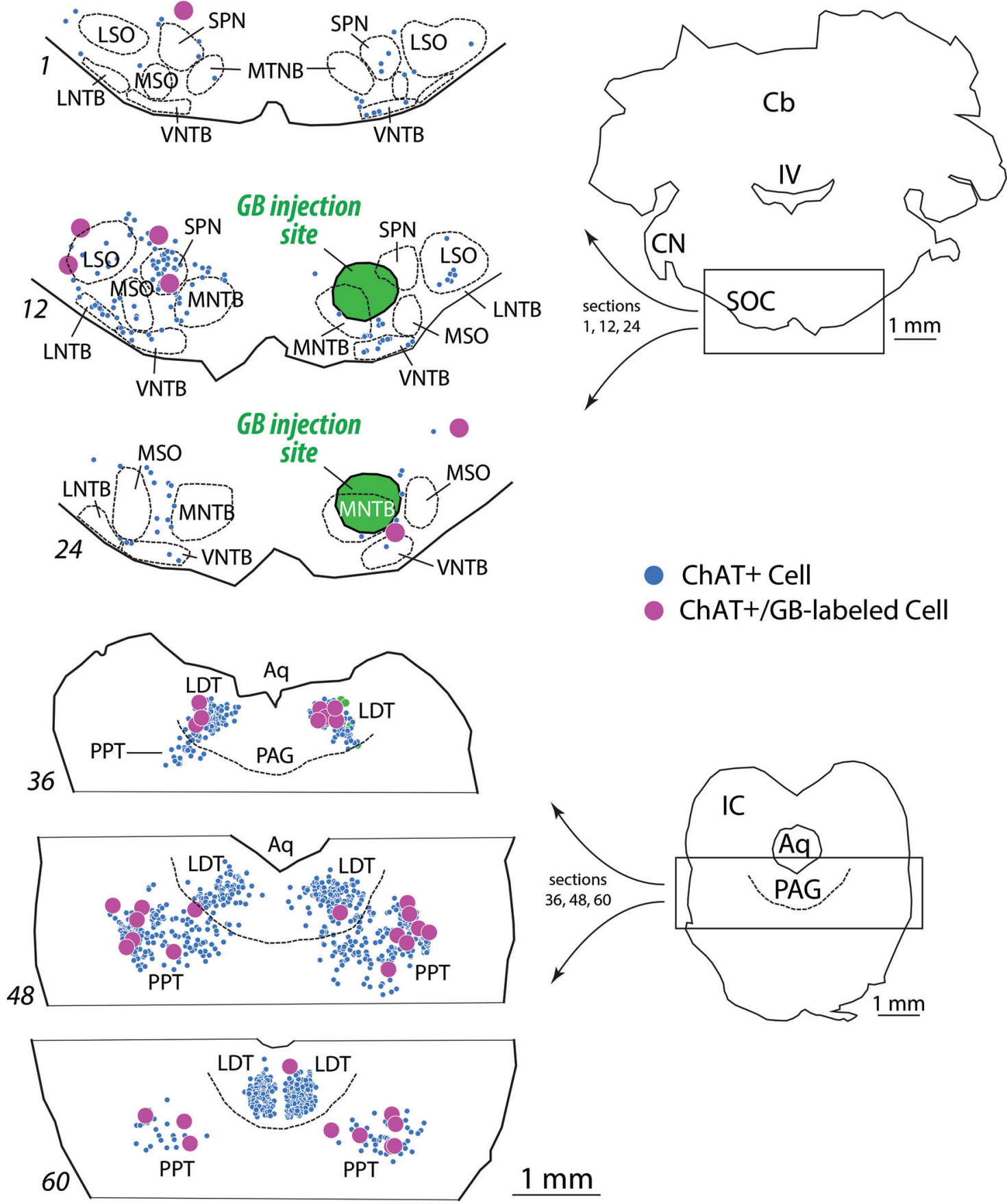

Figure 9. A plot of every 12th section through the brainstem showing the distribution of $\mathrm{ChAT}^{+}$tracer-labeled cells in the SOC (sections 1-24) and PMT (sections 36-60) in a representative case with a green RetroBeads deposit in the right SOC. This deposit included portions of the SPN in addition to the MNTB. Large magenta circles represent ChAT ${ }^{+}$retrogradely labeled cells. Cyan circles represent $\mathrm{ChAT}^{+} /$tracer-negative cells. Additional tracer-labeled cells were ChAT-negative (data not shown). Right, Full sections indicate the regions (rectangles) shown in the plots. IV, Fourth ventricle; Aq, cerebral aqueduct; Cb, cerebellum; GB, green RetroBeads; LDT, laterodorsal tegmental nucleus; LNTB, lateral nucleus of the trapezoid body; PAG, periaqueductal gray; VNTB, ventral nucleus of the trapezoid body.

to MNTB (Albrecht et al., 2014). The SOC also contains cholinergic olivocochlear neurons and a population of cholinergic neurons that project to the $\mathrm{CN}$ but not to the cochlea (Sherriff and Henderson, 1994; Gómez-Nieto et al., 2008). We could not determine whether the SOC projections to the MNTB arise from one of these two cholinergic groups, or whether a third population exists. Medial olivocochlear cells would seem to be an unlikely candidate for projections to the MNTB; they have axon collateral branches that innervate parts of the $\mathrm{CN}$ and vestibular nuclei, but they apparently lack collateral projections to other regions (Brown et al., 1988). The "non-olivocochlear" cholinergic SOC cells that project to the $\mathrm{CN}$ are likely sources of ACh to cochlear root neurons, spherical bushy cells, and possibly $\mathrm{T}$ stellate cells, but we are unaware of any evidence that they project to targets other than the CN (Fujino and Oertel, 2001; GómezNieto et al., 2008; Goyer et al., 2016; Gillet et al., 2018). Projections to the MNTB from cholinergic cells in and around the LSO raise a question of collateral projections of lateral olivocochlear cells (the only known cholinergic cells in this region). Ryan et al. (1990) suggested that lateral olivocochlear cells have 


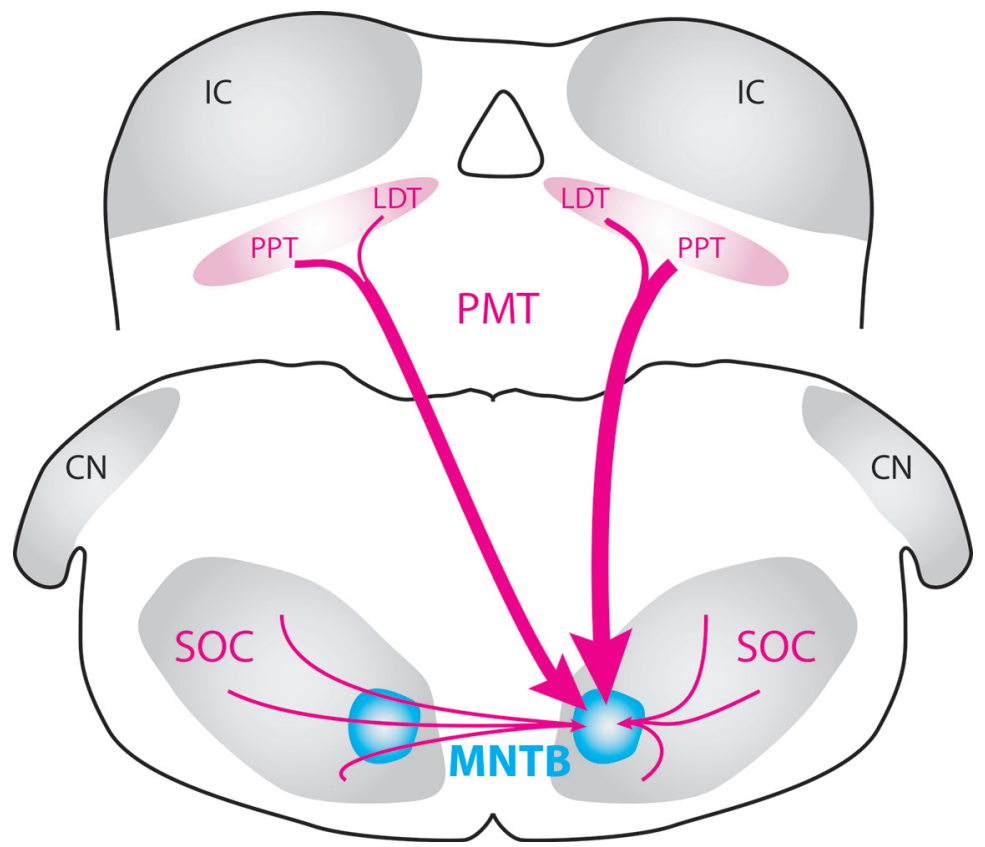

Figure 10. Schematic illustration of cholinergic inputs to a single MNTB. Arrow thickness indicates relative size of the projection as indicated by the number of projecting cells in the source nuclei. The largest projections originate from the pontomesencephalic tegmental nuclei (PMT), including the pedunculopontine tegmental nucleus and the laterodorsal tegmental nucleus. Smaller cholinergic projections originate from cells in the SOC, both ipsilateral and contralateral to the targeted MNTB.

collateral projections to the $\mathrm{CN}$ that could modulate ascending circuits (including, perhaps, those that provide input to the MNTB). However, there is no evidence for collateral projections of lateral olivocochlear cells to olivary nuclei. It will be interesting in future studies to determine whether the projections to MNTB arise as collaterals from cholinergic cells that project to the cochlea or $\mathrm{CN}$.

We also identified a prominent input from the PMT. The PMT participates in a variety of functions, including novelty detection, sensory gating, reward, arousal, attention, and auditory plasticity (Koyama et al., 1994; Luo and Yan, 2013; Gut and Winn, 2016; Cisse et al., 2018). Furthermore, it projects broadly in the auditory pathway, although projections to SOC have not been reported (Schofield et al., 2011). Studies have shown that a major target of SOC neurons, the IC, receives cholinergic input from the PMT. In IC, ACh modulated sound-evoked responses but did not affect spontaneous activity (Farley et al., 1983; Habbicht and Vater, 1996). The PMT also projects to the CN, where it may modulate globular bushy cells that provide input to the MNTB (Mellott et al., 2011; Gillet et al., 2018). Interestingly, PMT is activated on acoustic stimulation (Koyama et al., 1994; Reese et al., 1995a, b), and remains a possible source of soundevoked ACh input. The role of the bilateral PMT projection as well as the apparent input from the SOC in MNTB function urge future investigation.

\section{Differential cholinergic modulation of pure tone and noise responses}

Interestingly, while tone responses were strongly modulated, noise responses and spontaneous activity were relatively unaffected by ACh (Figs. 5B, 6G). This stimulus-dependent modulation may be a consequence of the efficacy of each stimulus in driving sustained responses. Low-frequency MNTB neurons entrain to tone signals with regular phase-locked discharges, whereas high-frequency neurons typically respond with vigorous sustained firing to $\mathrm{CF}$ tones. Noise stimuli evoke temporally dispersed responses with higher thresholds. We showed that ACh preferentially influences spiking in the sustained portion of tone responses compared with onset (Fig. 3D). It is reasonable to speculate that one function of $\mathrm{ACh}$ is that it preserves firing as the calyx synapse undergoes substantial depression at high sustained FR (Hermann et al., 2007). Noise-evoked responses and spontaneous activity exhibit stochastic interval distributions that may enable recovery from depression, even at this high safety-factor synapse and, as such, are less dependent on ACh to preserve response fidelity (Forsythe et al., 1998; Oline and Burger, 2014). The maximum noise-evoked sparse discharge pattern was comparable in rate to that evoked by pure tones near threshold (Fig. 6A). If the primary role of $\mathrm{ACh}$ is to enhance transmission at the calyx during synaptic depression, a steady-state recruitment of ACh during sparsely distributed noise responses may simply not be apparent.

\section{Convergence of $\alpha 7$ and $\alpha 4 \beta 2$ nAChR-mediated effects in MNTB neurons}

In this study, we probed the modulatory contributions of both $\alpha 7$ and $\alpha 4 \beta 2 \mathrm{nAChRs}$ in MNTB. Both nAChRs cast similar effects on FR, intensity encoding efficacy, and signal detection. We showed that calyceal efficacy was improved by both endogenous $\alpha 7$ and $\alpha 4 \beta 2$ $\mathrm{nAChR}$ activity, but it is not clear on the cellular level what the mechanistic underpinnings of this effect were. Both receptors are critical to a broad range of functions via presynaptic and postsynaptic effects throughout the brain (Levin et al., 2006). In hippocampus, activation of $\alpha 7 \mathrm{nAChRs}$ has been shown to enhance glutamate release (Cheng and Yakel, 2014, 2015). In the dorsal raphe nucleus, presynaptic $\alpha 4 \beta 2 \mathrm{nAChRs}$ have been shown to increase transmitter release (Garduno et al., 2012). Our in vivo approach does not permit assessment of such mechanisms; however, sequential antagonist application resulted in additive spike suppression (Fig. 3C), suggesting that the two receptors may affect more than one aspect of calyx physiology.

The only functional distinction between receptors detected in this study was that blocking $\alpha 7 \mathrm{nAChRs}$ increased the FSL of MNTB, whereas blocking $\alpha 4 \beta 2$ nAChRs showed no effect. However, first spike jitter did not change significantly after blocking $\alpha 7$ nAChRs. $\alpha 7 \mathrm{nAChRs}$ are endowed with relatively faster kinetics than $\alpha 4 \beta 2$ nAChRs (Alkondon et al., 1999). These differences may indicate that blocking $\alpha 7$ nAChRs preferentially influences transient features of the response compared with $\alpha 4 \beta 2$ (Albuquerque et al., 1997; Stanchev and Sargent, 2011; Corradi and Bouzat, 2016). Unfortunately, dynamics of the ACh modulation cannot be resolved with the current methods, so future in vitro studies are needed to reveal differential functions between the receptors.

\section{Implications of cholinergic modulation at MNTB for auditory processing}

MNTB is the major source of contralaterally derived inhibition to principal neurons in several SOC nuclei. This inhibition is crucial to their computational reliability and precision. Among 
these nuclei, MSO computes interaural time disparity, whereas LSO computes interaural intensity disparity (Rayleigh, 1907; Goldberg and Brown, 1969; Spangler et al., 1985; Adams and Mugnaini, 1990; Yin and Chan, 1990; Park et al., 1996; Tollin, 2003). Both cues are important for determining sound source location, and both derive their response functions, in part, because of prominent MNTB input. Thus, the relative strength of MNTB-derived inhibition plays an important computational role in sound location computing neurons, and the cholinergic contribution to MNTB output could be particularly impactful in shaping sound-evoked responses of these neurons.

In addition to binaural computations, MNTB is known to dramatically influence SPN responses. SPN responds to gaps in signals, thus encoding duration and termination of sounds (Kopp-Scheinpflug et al., 2011). The stereotypical offset response of SPN neurons arises from the termination of sound-evoked MNTB inhibition. Our study suggests that the cholinergic suppression of MNTB could directly influence offset encoding in SPN. Overall, our conclusions regarding cholinergic contributions to temporal processing are consistent with a recent finding in $\alpha 7 \mathrm{nAChR}$ KO mice showing manifestations of loss of acoustic temporal acuity (Felix et al., 2019).

\section{Cholinergic effects on the lower-ordered neurons in the brain}

The cholinergic influences on MNTB described here are a novel manifestation of the classical role of ACh as a neuromodulator (Schofield and Hurley, 2018). Prevalent in the brain, ACh has been found to potently affect neurotransmitter release, govern neuron excitability, and promote synaptic plasticity (Hill et al., 1993; Klein and Yakel, 2006; McGranahan et al., 2011; Feduccia et al., 2012; Yan et al., 2018). These observations throughout the brain render ACh a versatile neuromodulator in synaptic transmission physiologically, and functionally a key factor in governing rewarding, learning, memory, and emotion. Our study sheds light on ACh's role in modulating ascending auditory input in brainstem circuitry and contributes to a more holistic understanding of modulatory influences in auditory function specifically, and sensory processing in general.

\section{References}

Adams JC, Mugnaini E (1990) Immunocytochemical evidence for inhibitory and disinhibitory circuits in the superior olive. Hear Res 49:281-298.

Albrecht O, Dondzillo A, Mayer F, Thompson JA, Klug A (2014) Inhibitory projections from the ventral nucleus of the trapezoid body to the medial nucleus of the trapezoid body in the mouse. Front Neural Circuits 8:83.

Albuquerque EX, Alkondon M, Pereira EF, Castro NG, Schrattenholz A, Barbosa CT, Bonfante-Cabarcas R, Aracava Y, Eisenberg HM, Maelicke A (1997) Properties of neuronal nicotinic acetylcholine receptors: pharmacological characterization and modulation of synaptic function. J Pharmacol Exp Ther 280:1117-1136.

Alkondon M, Pereira EF, Eisenberg HM, Albuquerque EX (1999) Choline and selective antagonists identify two subtypes of nicotinic acetylcholine receptors that modulate GABA release from CA1 interneurons in rat hippocampal slices. J Neurosci 19:2693-2705.

Altieri SC, Zhao T, Jalabi W, Maricich SM (2014) Development of glycinergic innervation to the murine LSO and SPN in the presence and absence of the MNTB. Front Neural Circuits 8:109.

Banks MI, Smith PH (1992) Intracellular recordings from neurobiotin-labeled cells in brain slices of the rat medial nucleus of the trapezoid body. J Neurosci 12:2819-2837.

Beiderbeck B, Myoga MH, Muller NI, Callan AR, Friauf E, Grothe B, Pecka M (2018) Precisely timed inhibition facilitates action potential firing for spatial coding in the auditory brainstem. Nat Commun 9:1771.
Borst JG, Helmchen F, Sakmann B (1995) Pre- and postsynaptic whole-cell recordings in the medial nucleus of the trapezoid body of the rat. J Physiol 489:825-840.

Brand A, Behrend O, Marquardt T, McAlpine D, Grothe B (2002) Precise inhibition is essential for microsecond interaural time difference coding. Nature 417:543-547.

Brown MC, Liberman MC, Benson TE, Ryugo DK (1988) Brainstem branches from olivocochlear axons in cats and rodents. J Comp Neurol 278:591-603.

Burger RM, Pollak GD (2001) Reversible inactivation of the dorsal nucleus of the lateral lemniscus reveals its role in the processing of multiple sound sources in the inferior colliculus of bats. J Neurosci 21:4830-4843.

Cheng Q, Yakel JL (2014) Presynaptic alpha7 nicotinic acetylcholine receptors enhance hippocampal mossy fiber glutamatergic transmission via PKA activation. J Neurosci 34:124-133.

Cheng Q, Yakel JL (2015) The effect of alpha7 nicotinic receptor activation on glutamatergic transmission in the hippocampus. Biochem Pharmacol 97:439-444.

Cisse Y, Toossi H, Ishibashi M, Mainville L, Leonard CS, Adamantidis A, Jones BE (2018) Discharge and role of acetylcholine pontomesencephalic neurons in cortical activity and sleep-wake states examined by optogenetics and juxtacellular recording in mice. eNeuro 5:ENEURO.027018.2018.

Colburn HS, Carney LH, Heinz MG (2003) Quantifying the information in auditory-nerve responses for level discrimination. J Assoc Res Otolaryngol 4:294-311.

Coleman WL, Fischl MJ, Weimann SR, Burger RM (2011) GABAergic and glycinergic inhibition modulate monaural auditory response properties in the avian superior olivary nucleus. J Neurophysiol 105:2405-2420.

Corradi J, Bouzat C (2016) Understanding the bases of function and modulation of alpha7 nicotinic receptors: implications for drug discovery. Mol Pharmacol 90:288-299.

Dondzillo A, Thornton JL, Tollin DJ, Klug A (2013) Manufacturing and using piggy-back multibarrel electrodes for in vivo pharmacological manipulations of neural responses. J Vis Exp 71:e4358.

Farley GR, Morley BJ, Javel E, Gorga MP (1983) Single-unit responses to cholinergic agents in the rat inferior colliculus. Hear Res 11:73-91.

Feduccia AA, Chatterjee S, Bartlett SE (2012) Neuronal nicotinic acetylcholine receptors: neuroplastic changes underlying alcohol and nicotine addictions. Front Mol Neurosci 5:83.

Felix RA 2nd, Chavez VA, Novicio DM, Morley BJ, Portfors CV (2019) Nicotinic acetylcholine receptor subunit alpha7-knockout mice exhibit degraded auditory temporal processing. J Neurophysiol 122:451-465.

Forsythe ID, Tsujimoto T, Barnes-Davies M, Cuttle MF, Takahashi T (1998) Inactivation of presynaptic calcium current contributes to synaptic depression at a fast central synapse. Neuron 20:797-807.

Froemke RC, Merzenich MM, Schreiner CE (2007) A synaptic memory trace for cortical receptive field plasticity. Nature 450:425-429.

Fujino K, Oertel D (2001) Cholinergic modulation of stellate cells in the mammalian ventral cochlear nucleus. J Neurosci 21:7372-7383.

Garduno J, Galindo-Charles L, Jimenez-Rodriguez J, Galarraga E, Tapia D, Mihailescu S, Hernandez-Lopez S (2012) Presynaptic alpha4beta2 nicotinic acetylcholine receptors increase glutamate release and serotonin neuron excitability in the dorsal raphe nucleus. J Neurosci 32:1514815157.

Gillet C, Goyer D, Kurth S, Griebel H, Kuenzel T (2018) Cholinergic innervation of principal neurons in the cochlear nucleus of the Mongolian gerbil. J Comp Neurol 526:1647-1661.

Gleiss H, Encke J, Lingner A, Jennings TR, Brosel S, Kunz L, Grothe B, Pecka M (2019) Cooperative population coding facilitates efficient soundsource separability by adaptation to input statistics. PLoS Biol 17: e3000150.

Goldberg JM, Brown PB (1969) Response of binaural neurons of dog superior olivary complex to dichotic tonal stimuli: some physiological mechanisms of sound localization. J Neurophysiol 32:613-636.

Gómez-Nieto R, Rubio ME, López DE (2008) Cholinergic input from the ventral nucleus of the trapezoid body to cochlear root neurons in rats. J Comp Neurol 506:452-468.

Gómez-Nieto R, Sinex DG, Horta-Júnior Jde A, Castellano O, HerreroTurrión JM, López DE (2014) A fast cholinergic modulation of the primary acoustic startle circuit in rats. Brain Struct Funct 219:1555-1573. 
Goyer D, Kurth S, Gillet C, Keine C, Rubsamen R, Kuenzel T (2016) Slow cholinergic modulation of spike probability in ultra-fast time-coding sensory neurons. eNeuro 3:ENEURO.0186-16.2016.

Guinan JJ Jr, Li RY (1990) Signal processing in brainstem auditory neurons which receive giant endings (calyces of Held) in the medial nucleus of the trapezoid body of the cat. Hear Res 49:321-334.

Gut NK, Winn P (2016) The pedunculopontine tegmental nucleus: a functional hypothesis from the comparative literature. Mov Disord 31:615624 .

Habbicht H, Vater M (1996) A microiontophoretic study of acetylcholine effects in the inferior colliculus of horseshoe bats: implications for a modulatory role. Brain Res 724:169-179.

Happe HK, Morley BJ (2004) Distribution and postnatal development of alpha 7 nicotinic acetylcholine receptors in the rodent lower auditory brainstem. Brain Res Dev Brain Res 153:29-37.

Havey DC, Caspary DM (1980) A simple technique for constructing 'piggyback' multibarrel microelectrodes. Electroencephalogr Clin Neurophysiol 48:249-251.

Hermann J, Pecka M, von Gersdorff H, Grothe B, Klug A (2007) Synaptic transmission at the calyx of Held under in vivo like activity levels. J Neurophysiol 98:807-820.

Hill JA Jr, Zoli M, Bourgeois JP, Changeux JP (1993) Immunocytochemical localization of a neuronal nicotinic receptor: the beta 2-subunit. J Neurosci 13:1551-1568.

Holdstock LJ (1982) Auditory threshold, signal-to-noise ratio and signal detection theory. Curr Psychol Res 2:129-138.

Jacob SN, Nienborg H (2018) Monoaminergic neuromodulation of sensory processing. Front Neural Circuits 12:51.

Kadner A, Berrebi AS (2008) Encoding of temporal features of auditory stimuli in the medial nucleus of the trapezoid body and superior paraolivary nucleus of the rat. Neuroscience 151:868-887.

Klein RC, Yakel JL (2006) Functional somato-dendritic alpha7-containing nicotinic acetylcholine receptors in the rat basolateral amygdala complex. J Physiol 576:865-872.

Klug A, Bauer EE, Pollak GD (1999) Multiple components of ipsilaterally evoked inhibition in the inferior colliculus. J Neurophysiol 82:593-610.

Koka K, Tollin DJ (2014) Linear coding of complex sound spectra by discharge rate in neurons of the medial nucleus of the trapezoid body (MNTB) and its inputs. Front Neural Circuits 8:144.

Kopp-Scheinpflug C, Lippe WR, Dörrscheidt GJ, Rübsamen R (2003a) The medial nucleus of the trapezoid body in the gerbil is more than a relay: comparison of pre- and postsynaptic activity. J Assoc Res Otolaryngol $4: 1-23$.

Kopp-Scheinpflug C, Fuchs K, Lippe WR, Tempel BL, Rübsamen R (2003b) Decreased temporal precision of auditory signaling in Kcna1-null mice: an electrophysiological study in vivo. J Neurosci 23:9199-9207.

Kopp-Scheinpflug C, Tolnai S, Malmierca MS, Rübsamen R (2008) The medial nucleus of the trapezoid body: comparative physiology. Neuroscience 154:160-170.

Kopp-Scheinpflug C, Tozer AJ, Robinson SW, Tempel BL, Hennig MH, Forsythe ID (2011) The sound of silence: ionic mechanisms encoding sound termination. Neuron 71:911-925.

Koyama Y, Jodo E, Kayama Y (1994) Sensory responsiveness of 'broad-spike' neurons in the laterodorsal tegmental nucleus, locus coeruleus and dorsal raphe of awake rats: implications for cholinergic and monoaminergic neuron-specific responses. Neuroscience 63:1021-1031.

Kramer F, Griesemer D, Bakker D, Brill S, Franke J, Frotscher E, Friauf E (2014) Inhibitory glycinergic neurotransmission in the mammalian auditory brainstem upon prolonged stimulation: short-term plasticity and synaptic reliability. Front Neural Circuits 8:14.

Kuenzel T (2019) Modulatory influences on time-coding neurons in the ventral cochlear nucleus. Hear Res 384:107824.

Levin ED, McClernon FJ, Rezvani AH (2006) Nicotinic effects on cognitive function: behavioral characterization, pharmacological specification, and anatomic localization. Psychopharmacology (Berl) 184:523-539.

Lorteije JA, Rusu SI, Kushmerick C, Borst JG (2009) Reliability and precision of the mouse calyx of Held synapse. J Neurosci 29:13770-13784.

Lu T, Liang L, Wang X (2001) Temporal and rate representations of timevarying signals in the auditory cortex of awake primates. Nat Neurosci 4:1131-1138.
Luo F, Yan J (2013) Sound-specific plasticity in the primary auditory cortex as induced by the cholinergic pedunculopontine tegmental nucleus. Eur J Neurosci 37:393-399.

Macmillan NA, Creelman CD (2004) Detection theory: a user's guide. Abingdon, UK: Taylor \& Francis.

Marder E (2012) Neuromodulation of neuronal circuits: back to the future. Neuron 76:1-11.

McGehee DS, Heath MJ, Gelber S, Devay P, Role LW (1995) Nicotine enhancement of fast excitatory synaptic transmission in CNS by presynaptic receptors. Science 269:1692-1696.

McGranahan TM, Patzlaff NE, Grady SR, Heinemann SF, Booker TK (2011) alpha4beta2 nicotinic acetylcholine receptors on dopaminergic neurons mediate nicotine reward and anxiety relief. J Neurosci 31:10891-10902.

McLaughlin M, van der Heijden M, Joris PX (2008) How secure is in vivo synaptic transmission at the calyx of Held? J Neurosci 28:10206-10219.

Metherate R (2011) Functional connectivity and cholinergic modulation in auditory cortex. Neurosci Biobehav Rev 35:2058-2063.

Metherate R, Ashe JH (1993) Ionic flux contributions to neocortical slow waves and nucleus basalis-mediated activation: whole-cell recordings in vivo. J Neurosci 13:5312-5323.

Metherate R, Ashe JH, Weinberger NM (1990) Acetylcholine modifies neuronal acoustic rate-level functions in guinea pig auditory cortex by an action at muscarinic receptors. Synapse 6:364-368.

Mellott JG, Motts SD, Schofield BR (2011) Multiple origins of cholinergic innervation of the cochlear nucleus. Neuroscience 180:138-147.

Mogg AJ, Whiteaker P, McIntosh JM, Marks M, Collins AC, Wonnacott S (2002) Methyllycaconitine is a potent antagonist of alpha-conotoxinMII-sensitive presynaptic nicotinic acetylcholine receptors in rat striatum. J Pharmacol Exp Ther 302:197-204.

Oertel D, Fujino K (2001) Role of biophysical specialization in cholinergic modulation in neurons of the ventral cochlear nuclei. Audiol Neurootol 6:161-166.

Oline SN, Burger RM (2014) Short-term synaptic depression is topographically distributed in the cochlear nucleus of the chicken. J Neurosci 34:1314-1324.

Oliver DL, Beckius GE (1993) Ascending projections from the cochlear nucleus to the inferior colliculus and their interactions with projections from the superior olivary complex. In: The mammalian cochlear nuclei: organization and function (Merchán MA, Juiz JM, Godfrey DA, Mugnaini E, eds), pp 335-347. New York: Springer.

Park TJ, Grothe B, Pollak GD, Schuller G, Koch U (1996) Neural delays shape selectivity to interaural intensity differences in the lateral superior olive. J Neurosci 16:6554-6566.

Pecka M, Brand A, Behrend O, Grothe B (2008) Interaural time difference processing in the mammalian medial superior olive: the role of glycinergic inhibition. J Neurosci 28:6914-6925.

Rayleigh L (1907) XII. On our perception of sound direction. The London, Edinburgh, and Dublin Philosophical Magazine and Journal of Science 13:214-232.

Reese NB, Garcia-Rill E, Skinner RD (1995a) Auditory input to the pedunculopontine nucleus: II. Unit responses. Brain Res Bull 37:265-273.

Reese NB, Garcia-Rill E, Skinner RD (1995b) The pedunculopontine nucleus: auditory input, arousal and pathophysiology. Prog Neurobiol 47:105133.

Rosen MJ, Semple MN, Sanes DH (2010) Exploiting development to evaluate auditory encoding of amplitude modulation. J Neurosci 30:15509-15520.

Ryan AF, Keithley EM, Wang ZX, Schwartz IR (1990) Collaterals from lateral and medial olivocochlear efferent neurons innervate different regions of the cochlear nucleus and adjacent brainstem. J Comp Neurol 300:572582.

Scheler G (2004) Regulation of neuromodulator receptor efficacy: implications for whole-neuron and synaptic plasticity. Prog Neurobiol 72:399415.

Schofield BR, Hurley L (2018) Circuits for modulation of auditory function. In: The mammalian auditory pathways: synaptic organization and microcircuits (Oliver DL, Cant NB, Fay RR, Popper AN, eds), pp 235-267. Cham: Springer.

Schofield BR, Motts SD, Mellott JG (2011) Cholinergic cells of the pontomesencephalic tegmentum: connections with auditory structures from cochlear nucleus to cortex. Hear Res 279:85-95.

Sherriff FE, Henderson Z (1994) Cholinergic neurons in the ventral trapezoid nucleus project to the cochlear nuclei in the rat. Neuroscience 58:627-633. 
Simpson AJ, Fitter MJ (1973) What is the best index of detectability? Psychol Bull 80:481-488.

Sollini J, Chadderton P (2016) Comodulation enhances signal detection via priming of auditory cortical circuits. J Neurosci 36:12299-12311.

Sommer I, Lingenhohl K, Friauf E (1993) Principal cells of the rat medial nucleus of the trapezoid body: an intracellular in vivo study of their physiology and morphology. Exp Brain Res 95:223-239.

Sottile SY, Hackett TA, Cai R, Ling L, Llano DA, Caspary DM (2017) Presynaptic neuronal nicotinic receptors differentially shape select inputs to auditory thalamus and are negatively impacted by aging. J Neurosci 37:11377-11389.

Spangler KM, Warr WB, Henkel CK (1985) The projections of principal cells of the medial nucleus of the trapezoid body in the cat. J Comp Neurol 238:249-262.

Stanchev D, Sargent PB (2011) $\alpha 7$-containing and non- $\alpha 7$-containing nicotinic receptors respond differently to spillover of acetylcholine. J Neurosci 31:14920-14930.

Stange A, Myoga MH, Lingner A, Ford MC, Alexandrova O, Felmy F, Pecka M, Siveke I, Grothe B (2013) Adaptation in sound localization: from $\mathrm{GABA}(\mathrm{B})$ receptor-mediated synaptic modulation to perception. Nat Neurosci 16:1840-1847.

Teschner MJ, Seybold BA, Malone BJ, Huning J, Schreiner CE (2016) Effects of signal-to-noise ratio on auditory cortical frequency processing. J Neurosci 36:2743-2756.
Tollin DJ (2003) The lateral superior olive: a functional role in sound source localization. Neuroscientist 9:127-143.

Tolnai S, Hernandez O, Englitz B, Rubsamen R, Malmierca MS (2008) The medial nucleus of the trapezoid body in rat: spectral and temporal properties vary with anatomical location of the units. Eur J Neurosci 27:25872598.

Wang Y, Ren C, Manis PB (2010) Endbulb synaptic depression within the range of presynaptic spontaneous firing and its impact on the firing reliability of cochlear nucleus bushy neurons. Hear Res 270:101-109.

Whitmer WM, Akeroyd MA (2011) Level discrimination of speech sounds by hearing-impaired individuals with and without hearing amplification. Ear Hear 32:391-398.

Willmore BD, Cooke JE, King AJ (2014) Hearing in noisy environments: noise invariance and contrast gain control. J Physiol 592:3371-3381.

Woolf NJ, Butcher LL (1986) Cholinergic systems in the rat brain: III. Projections from the pontomesencephalic tegmentum to the thalamus, tectum, basal ganglia, and basal forebrain. Brain Res Bull 16:603-637.

Yan Y, Peng C, Arvin MC, Jin XT, Kim VJ, Ramsey MD, Wang Y, Banala S, Wokosin DL, McIntosh JM, Lavis LD, Drenan RM (2018) Nicotinic cholinergic receptors in VTA glutamate neurons modulate excitatory transmission. Cell Rep 23:2236-2244.

Yin TC, Chan JC (1990) Interaural time sensitivity in medial superior olive of cat. J Neurophysiol 64:465-488. 